\title{
Testing the behaviour of Australian brushtail possums (Trichosurus vulpecula) to candidate semiochemicals from conspecifics' urine.
}

\author{
Lauren Mockett
}

2017

A Thesis Presented in Partial Fulfilment of the Requirements of a Master of Science 
Abstract

Introduction

Aims

Testing the observer effect when behavioural sampling

Testing the behavioural response of possums to semiochemicals

General discussion

References 


\section{Acknowledgements}

I would like to thank all those who have assisted me in completing this thesis, in particular Dr Wayne Linklater, my supervisor who helped me design the project and has given invaluable advice throughout the project, particularly on the statistical analysis and drafts. I would also like to thank Post-Doctoral Fellow Dr Christine Stockum for her advice over the course of my Masters, training me in looking after the possums, and providing the urine based compounds for this experiment. Many thanks also to Mike Jackson for allowing me the use of his food compounds and showing me how he created them. Last, but not least, thanks to my partner Nick, parents, friends and colleagues for their encouragement, unwavering support, and for believing in me. 


\section{Abstract}

The Australian brushtail possum (Trichosurus vulpecula) is a prolific introduced mammalian pest. Current pest control methods involve traps and poisons, but are proving to be ineffective long term solutions. As semiochemical lures are thought to be more attractive than food-based lures at low densities, researchers are attempting to utilize semiochemicals for kill traps. The objectives of this thesis were to create a testing protocol for use in a research colony of possums and use that protocol to test the attractiveness of semiochemicals found in possum urine that had been positively associated with possum attraction and interest in urine.. I hypothesised that there would be an observer effect present in the colony due to the nature of the colony husbandry protocols. There was no statistically significant observer effect present in the colony for eating, interaction, sitting, grooming or enclosure use (front or back). However, there was a trend (across the colony) that sitting and grooming increased in the presence of an observer. From these results, I designed an active presentation protocol for testing semiochemicals. I predicted that the most attractive compounds would belong to the acids and alcohol chemical groups. Overall there was no statistically significant difference between the semiochemicals. However, when taken individually there was clear evidence that five of the semiochemicals (belonging to the ketone, alcohol and phenol chemical groups) were more attractive than their control and the standard lure. It has been shown in this thesis that the attractiveness of semiochemicals can be tested in a small research colony. However, limits on colony size greatly reduce statistical power. For future studies, I would recommend increasing the sample size or instead developing field-based bioassays capable of being repeated across a greater number of sites, populations and therefore, individual possums. 


\section{Chapter 1: A General Introduction to Animal Communication, Semiochemicals and Australian brushtail possum Ecology.}

\section{Animal communication}

Animal communication is the transfer of information from a signaller to a receiver (Mayard-Smith and Harper, 1995; Bradbury and Vehrencamp, 1999; Seyfarth and Cheney, 2003). The purpose of communication is to elicit a change in behaviour from the receiver in response to information provided by the signaller (Marler, 1967; Endler, 1993; Bradbury and Vehrencamp, 1999). Communication between animals can occur through signals or cues (Marler, 1967; Saleh et al., 2007; Bro-Jorgensen, 2009). Signals are defined as traits that have evolved to elicit a hardwired response from the receiver (Candolin, 2003; Wiley, 2006). A signal is an intentional form of communication left by the signaller (Candolin, 2003) (e.g. mating calls in song birds (Mennill et al, 2002; Searcy, 1992). By contrast a cue is an incidental feature in the environment. A cue does not have a specific meaning to a receiver (whereas a signal does) but still provides information the receiver can act on (Marler, 1967; Candolin, 2003; Wiley, 2006). For example, a female bird may use the wear and tear on feather margins of a potential mate to assess mate quality (Hasson, 1997).

Whether a signal or a cue, all communication transfers information (Endler, 1993; Bradbury and Vehrencamp, 1999). This information can be visual, vocal or olfactory (Osorio and Vorobyev, 2008). Each form of communication is utilised in different ways, and in different amounts by animals (Endler, 1993). A visual signal is a signal detected by the photoreceptors of the receiver (Osorio and Vorobyev, 2008). Thus, a visual signal requires the receiver to be within the line of sight of the signaller 
(Osorio and Vorobyev, 2008). A visual signal can be one of, or a combination, of the following: an ornament (such as antlers) (Candolin, 2003), colour pattern (e.g. wing colour patches) (Candolin, 2003) or display (such as a courtship dance) (Osorio and Vorobyev, 2008). Perhaps the most well-known example of visual communication is the mating display in the peacock (Pavo cristatus) (Dakin and Montgomerie, 2011). A peacock's elaborate train is a visual signal to the peahen of mate quality (Candolin, 2003; Dakin and Montgomerie, 2011). Vocal signals are produced via soundwaves, and so the receiver is not required to be within the line of sight of the signaller, however they still need to be close enough to receive the signal (Neumann et al., 2010). Male-male song contests in territorial song birds are a vocal signal used to establish territory between males, but also used by females in mate choice (Kroodsma and Byers, 1991; Searcy, 1992; Candolin, 2003). Olfactory signals are chemical signals left by the signaller for the receiver (Eisenberg and Kleiman, 1972). For olfactory communication, the signaller and receiver can be separated both in space and time (Eisenberg and Kleiman, 1972; Humphries et al., 1999). Scent marking is an example of an olfactory signal used throughout the animal kingdom for social organisation and partitioning of space (Eisenberg and Kleiman, 1972; Gosling, 1982; Heymann, 1998; Goosling and Roberts, 2001).

Regardless of the form of communication used, vocal, visual and olfactory signals all convey information about the signaller to the receiver (Marler, 1967; Endler, 1993; Bradbury and Vehrencamp, 1999). Information about the signaller's sex, health, dominance status and reproductive status can all be conveyed through signals (Eisenberg and Kleiman, 1972; Preuschoft and Schaik, 2000). Female mate choice is highly influenced by signals (Mennill et al., 2002). For example, in the peacock, mate selection is based on the length of the male's train and number of eye 
spots. Length and eye spot number in peacocks has been linked to better recovery after an immune response, suggesting males with longer tails and more eye spots haver better immune system genes and would, therefore, make a better mate (Dakin and Montgomerie, 2011). Another signal used in mate choice is mating calls (Wich et al., 2003; Kitchen et al., 2003). Mating calls can be used by males to attract mates, defend a mate or territory against competing males or mate identification (Wich et al.,2003; Kitchen et al.,2003). Songbirds are well known for having an elaborate repertoire of mating calls used for attracting mates (Kroodsma and Byers, 1991; Menhill and Ratcliff, 2002; Wich et al.,2003; Nuemann et al., 2010). Females in many songbird species will choose a male with large and complex repertoires, that can be driven by sexual and/or natural selection (Kroodsma and Byers, 1991; Mennill et al., 2002).

The dominance status of the signaller can be portrayed through visual, vocal and olfactory signals (Preuschoft and Schaik, 2000). Displays of aggression, loud vocal calls and scent marking are all utilised by animals to communicate their dominance status to both immediate competitors, but also potential competitors (receivers separated temporally or geographically from the signaller) (Humphries et al.,1999). In territorial animals, the animals are not able to defend all their territory from competitors at once. By leaving an olfactory signal through scent marking the signaller can let any potential receivers know the area is occupied and regularly patrolled (Hurst and Beynon, 2004). The action of the receiver upon receiving the signal can vary depending on the sex of the signaller and sex of the receiver (Heymann, 1998; Seyfarth and Cheny, 2003). Same sex signalling (male-male or female-female) often communicates dominance and territorialism to the receiver with the desire of ensuring the receiver will have an appropriate response (Preuschoft and 
Schaik, 2000). For example, avoiding an area as to avoid a more dominant animal or alternatively, seek out and engage with the signaller to enhance the receiver's dominance status or gain control of resources (Heymann, 1998; Preuschoft and Schaik, 2000). Opposite sex signalling (male-female or female-male) will communicate reproductive status to the receiver letting it know the signaller is receptive to mating (Heymann, 1998).

All animal communication has associated costs and benefits (Hasson, 1997). It can be assumed in all signals the benefits outweigh the costs otherwise evolution would have selected other signals with benefits which did outweigh the costs. Signals are energetically and behaviourally costly to produce for the signaller through direct energetic cost and an indirect increase in risk (Hasson, 1997). Once a signal is made, the signaller can rarely control who receives the signal and is at risk of the signal being noticed by unintended receivers (competitors, predators and parasitoids) (Grodin and Davis, 1995; Zuk and Kolluru, 1998). Peacock trains (Dakin and Montgomerie, 2011), songbird mating calls (Kroodsma and Byers, 1991; Wich et al., 2003) and proteins found in scent marks are all examples of costly signals (Heymann, 1998). However, the long-term survival and reproductive benefit of these signals ultimately outweighs their cost (Hasson, 1997).

An unintended receiver responding to a signal is eavesdropping on that signal and interpreting it as a cue (Hughes et al, 2010). Eavesdropping can occur within a trophic level through closely related species intercepting the signal of another species as a cost-free way of gathering information (Grodin and Davis, 1995; Hughes et al., 2010, Hughes et al., 2012). Eavesdropping can also occur across trophic levels from predators and parasitoids exploiting the signals of their prey (Zuk and Kolluru, 1998, Hughes et al., 2010, Hughes et al., 2012). It would be beneficial for predators and 
parasitoids to eavesdrop on their preys' signals as it would reduce the energetic cost of locating their prey (Grodin and Davis, 1995; Zuk and Kolluru, 1998; Hughes et al., 2010, Hughes et al., 2012). For example, the egg parasitoid Telenomus podisi locates its prey by eavesdropping on its vibratory signals which are used as a form of communication between male and female hosts (Laumann et al.,2007).

Signals however are not always honest. A signaller can gain a lot of benefit from deceiving a receiver (Laidre, 2009). By using a dishonest signal, a signaller may be able to outcompete a competitor for mates or resources, avoid predation (Johnstone and Grafen, 1993; Szamado, 1998; Rowell et al., 2006; Laidre, 2009; Hughes et al., 2012) or win aggressive encounters they may not have otherwise (Johnstone and Grafen, 1993; Laidre, 2009). For example, in the Green Tree Frog (Hyla cinerea) large males have deeper calls. Since large males are more likely to win aggressive encounters, smaller males have an incentive to lower the pitch of their calls to match that of the larger males. Thus, making it seem larger than they are (Bee et al., 2000). How dishonest signals can prevail in animal communicate is a topic of debate amongst behavioural ecologists (Szamado, 1998; Rowell et al., 2006; Whiting et al., 2009). Although there are benefits from dishonest signalling, if so many signals are dishonest, you can create a situation where so many signals are dishonest that they are ignored (Johnstone and Grafen, 1993; Rowell et al., 2006; Laidre, 2009; Whiting et al., 2009). The result would be a breakdown of communication (Whiting et al., 2009). It has been theorised that dishonest signals can exist because most signals are in fact honest (Johnstone and Grafen, 1993; Rowell et al., 2006; Laidre, 2009).

\section{Semiochemicals}


Olfactory communication is defined as the process by which a chemical signal is transmitted by a signaller to a receiver (Eisenberg and Kleiman, 1972). Olfactory communication can occur through air and water (Bossert and Wilson, 1963). The chemicals used in olfactory communication have been traditionally split into "pheromones" (chemicals used for communication within a species) and "allomones" (chemicals used for communication across species) (Brennan and Keverne, 2004; Bigiani, 2005; Archunan, 2009). However, the use of these terms is highly debated as more research is conducted into animal olfactory signals (Brennan and Zufall, 2006). Pheromones have been researched in insects since the 1960's and since then thousands of insect pheromones have been identified (Levison, 1975; Renou and Gurrero et al, 2000; Mennill et al, 2011). By comparison, research into mammalian pheromones has been slow, mostly due to the complexity in mammalian olfactory signalling and behaviour (Brennan and Kendrick, 2006). As research continues to expand scientific knowledge it is becoming less clear as to what exactly qualifies as a pheromone (Brennan and Keverne, 2004). In this thesis, I will use the term semiochemicals to describe chemical signals and cues and, for convenience, will include those that include more complex molecules like proteins.

Olfactory communication does have its advantages and disadvantages. For example, there can be a long period between when the signal is emitted by the signaller and when it detected by the receiver (Hasson, 1997). Semiochemical signals do however last longer in the environment than visual or vocal signals, and perhaps most importantly, can be active signals in the absence of the signaller (Brennan and Keverne, 2004).

Semiochemicals are found throughout the animal kingdom and are used extensively by mammals (Brennan and Kendrick, 2006; Hong Tan et al., 2014). They 
are used by mammals for a wide variety of behaviours including oestrus (opossums) (Zuri and Halpern, 2003), intraspecific communication (moles and hedgehogs) (Bigiani et al.,2005), territorialism (carnivores and ungulates) (Peters and Merch, 1975; Smith et al., 1989; Whittle et al.,2000) and social hierarchy (pigs) (Bigiani et al.,2005). Due to complications, which can arise out of researching semiochemicals in the natural environment and for pragmatic reasons, semiochemicals have been most extensively studied in animals more suitable to a laboratory environment, specifically hamsters, rats and mice (Hurst, 1990; Humpheries et al., 1999; Hurst and Beynon, 2004; Archunan, 2009). More specifically, reproductive and social hormones such as Aphrodisim (hamsters) (Brennan and Keverne, 2004) and major urinary proteins (MUPs) (Roberts et al., 2010) in mice have been the subject of particularly detailed study (Christensen, 1976; Hurst, 1990; Humpheries et al, 1999; Hurst and Beynon, 2004).

Most mammals detect semiochemicals through their vomeronasal organ (VNO) (Bossert and Wilson, 1963; Bigaini et al., 2005; Zarzo, 2007) (notably, this organ is absent in dolphins and is vestigial in old world monkeys, primates and humans) (Bigaini et al, .2005). The vomeronasal organ is a bony structure at the base of the septum and opens into the nasal cavity or mouth through a duct. Stimuli can enter through the mouth and nose into the lumen (a cavity inside the vomeronasal organ) which is filled with mucus (Bossert and Wilson, 1963; Bigiani et al., 2005; Zarzo, 2007). The lumen is covered in epithelial sensory cells which transmit the signal to the olfactory bulb in the brain via the first cranial nerve (Bossert and Wilson, 1963). There is believed to be "cross-talk" between the olfactory bulb and the amygdala, explaining why some semiochemicals can influence inexperienced 
individuals (for example, virgin mammal in mating contests) (Bigiani et al., 2005; Zarzo, 2007).

Semiochemicals come in a wide variety of chemical forms. However, the most important features are their molecular size and polarity (Archunan, 2009). These two factors help to determine the volatility of a semiochemical in air and water, respectively (Archunan, 2009). semiochemicals which are more volatile will also be smaller. The purpose of a pheromone can be linked to its volatility. Volatile semiochemicals are intended to attract or alarm the receiver so therefore they are highly volatile (Hurst et al., 2008). They can be effective at a distance as they can disperse through the environment quickly (e.g. methylthiomethanethiol in mice which is used to attract females) (Hurst, 1990; Hurst and Beynon, 2004). Semiochemicals which portray information about an individual are more likely to be non-volatile so they don't disperse and can be readily associated with the signaller or a place (e.g., MUPs in mice and rats) (Humpheries et al., 1999; Brennan and Keverne, 2004; Hurst and Beynon, 2004).

Semiochemicals which are highly volatile typically do not last as long in the environment as less volatile semiochemicals. One such example, where high volatility is traded for longevity is in scent marks (Archunan, 2009). Scent marks are designed to be active in the environment long after the signaller has left the area (Goosling and Roberts, 2001; Heymann, 1998). This trade off means scent marks are not just one semiochemical, but a mix of general odorants, semiochemicals and bodily secretions. semiochemicals, by necessity, will be the same across a species (Goosling, 1982). However, a scent mark which contains them varies between individuals (a signature mixture) (Heymann, 1998; Goosling and Roberts, 2001; Wyatt, 2010). A scent mark, therefore will contain two semiochemical components, long range volatile 
semiochemicals to attract the conspecific and short range non-volatile semiochemicals to convey information (Wyatt, 2010).

\section{Possum Ecology}

The Australian brushtail possum (Trichosurus vulpecula) (forthwith referred to as possums) were first introduced into New Zealand from Australia in the 1840's to establish a fur industry (Owen and Norton, 1995; Clinchy et al., 2004; Issac 2005). Possums are endemic to mainland Australia and are also found on several offshore islands (Eymann et al., 2006). Whilst many populations in Australia are experiencing a decline, possums have thrived in New Zealand forests, farms and some urban areas (Owen and Norton, 1995). They have adapted so well to the New Zealand environment they have been linked to the decline of many forest species including New Zealand native plants, birds and invertebrates. They have been classified as a pest species by the Department of Conservation (Norton, 1995; Issac, 2005).

Possums are arboreal nocturnal marsupials and primarily herbivores, but have also been known to eat meat, native birds and their eggs, and invertebrates (Owen and Norton, 1995). During the day, they nest in dens which are typically above ground in tree hollows (Day et al., 2000). Possums typically remain in their dens until half an hour after sunset, but they can be active in their dens for up to two hours before sunset (Cowan, 1989; Day et al., 2000). Undernourished or ill possums may become active in the afternoon to feed. In the wild, dens will typically house a single possum, but in captivity or when dens are in short supply, possums may share a den site (Day et al., 2000; Clinchy et al., 2004).

Even though possums are solitary animals, they have home ranges which often overlap (Cowan and Clout, 2000). A possum's home range is typically quite large and 
it normally takes two or three nights for an individual to cover its home range (Clout and Efford, 1984). A possum will have multiple den sites within its home range (Cowan, 1989; Cowan and Clout, 2000). Possum populations operate under a dominance hierarchy, with larger animals being dominant over smaller animals, and females dominant over males (Jolly et al., 1999). Unrelated females will mutually avoid each other, whilst males attempt to exclude other males from accessing females (Clinchy et al., 2004). If pairs of possums are ever seen in the wild they are most likely either two related females (often mother and daughter) or a female with a male consort. Female possums are aggressive towards males even in the breeding season. Males often spend 30-40 days consorting a female before she is ready to mate. Mating can occur all year round, however most births occur in April-June (Clout and Efford, 1984; Clinchy et al., 2004).

Juvenile possums will stay with their mother until they are around nine months of age. From then on, they will spend greater amounts of time away from their mother until they are independent and establish their own home range (Cowan and Clout, 2000; Clinchy et al., 2004). Males reach maturity around one-two years of age, whilst the first breeding age for females varies as reproduction is dependent on body condition and therefore, food supply (Salamon et al., 1999. Males will disperse further away from their mothers to establish a home range whilst females typically establish home ranges adjacent to their mothers (Little and Cowan, 1992; Cowan and Clout, 2000).

Possums primarily identify other individuals through smell and secondarily through vision. Possums have scent glands on the chin, sternum, paracloacal region and pouch. They use these sent glands to communicate with other individuals in the 
area and mark their home range (Salamon et al., 1999; McLean, 2014). The sternum and cloacal glands are larger on males than females (Woodhouse et al., 1994).

In New Zealand, adult possums have few natural predators. However feral cats will prey on possums. Stoats will scavenge from a dead possum. Also, stoats, moreporks and Australasian harriers will prey on young possums. In Australia, foxes are the primary predator of possums (Little and Cowan, 1992)

\section{Pest Management in New Zealand}

Prehistorically, New Zealand's islands were largely mammal free (except for two species of bat). Our terrestrial flora and fauna evolved without the influence of mammal predators. The introduction of mammals (through either hitchhiking with human settlers or being purposefully introduced) had destructive effect on some of our native flora and fauna (Parkes and Murphy, 2003).

The Polynesian rat (or Kiore) was one of the first to arrive in New Zealand around 2000 years ago, with the first (but failed) Maori colonisation (Parkes and Murphy, 2003). A second successful colonisation 900 years ago, introduced the domesticated dog (Parkes and Murphy, 2003). Mice, ship and Norwegian rats arrived latter with European settlers who also intentionally released deer, rabbits, hares and wallabies for hunting. Domestic stock such as pigs, goats, sheep, horses, cats and cattle were also able to establish feral populations when they escaped or were released from farms. Possums were introduced to start a fur industry (Cowan, 1993). To control previously introduced rabbit (which were now a pest) mustelids were introduced. Hedgehogs were also introduced to control invertebrate pests (Parkes and Murphy, 2003). 
The damage introduced mammalian pests have done is widely recognised (Crawford et al., 1998). They are managed for three main reasons: to protect native species and communities, to prevent the spread of domestic animal diseases like bovine Tuberculosis and to protect agricultural production value (Cowan, 1993; Parkes and Murphy, 2003). Due to their immense impact on native species and their ability to act as vectors for bovine tuberculosis and the damage caused to agriculture rats, mustelids and possums are the primary focus of pest management strategies (Parkes and Murphy, 2003).

Since their arrival in the 1840's Possums have had a large effect on both the New Zealand forest and the agricultural sector (Cowan, 1993; Owen and Norton, 1995). Possums are highly destructive folivores through their browsing in forests (Crawford et al., 1998). Possums are also the largest animal vector of bovine Tuberculosis in New Zealand. They act as a vector for the virus and enable it to spread between herds of cattle (Tompkins and Ramsey, 2007). Possums have also been linked to the decline of several native birds and invertebrates. By the 1990's possum populations had spread to inhabit $92 \%$ of New Zealand (Cowan et al., 2002).

Since the 1950's government departments, researchers and community conservation groups have been attempting to control possum populations through a variety of methods (Parkes and Murphy, 2003). Poisons (Eason and Jolly, 1993) and traps are the most common (Dix et al., 1994; Glen et al., 2014). Cyanide, Sodium fluroacetate (1080) and brodificoum are all poisons currently used to control possum (and other invasive mammal) populations (Morgan et al., 1995, Ross et al., 2000).

Cyanide was one of the first poisons used to control possum populations. It was applied to bait stations as a paste (Morgan et al., 1995; Eason and Jolly, 1993). 
Cyanide is no longer commonly used as it is not as effective as other methods (Morgan et al., 1995). Cyanide is less effective for two reasons. First, a poisons effectiveness can be driven by the baits texture and taste. Cyanide comes in a paste form and is quite bitter which makes it unappealing to animals. Second, it is ineffective at eradicating possum populations due to its tendency to induce "cyanide shyness" (Morgan et al., 1995). This is when neophobic animals have a natural primary aversion to the cyanide paste, but animals can also acquire secondary aversion by consuming a sub-lethal dose (Morgan et al., 1995).

When 1080 was first being used as a poison, secondary aversion was still a problem for many populations. To overcome this the type of aversion the bait was changed from a carrot based lure to a cereal based bait (Ross et al., 2000). Research has also shown pre-feeding is an important method of overcoming bait-shyness. Prefeeding involves dropping non-toxic bait prior to a toxic bait operation. Target animals that consume the non-toxic bait are more likely to consume the toxic bait once it has been dropped over the area (Ross et al., 2000; Parkes and Murphy, 2003).

Despite their effectiveness at reducing possum populations, concerns have been raised by both public conservation groups and land managers about the impact aerial 1080 operations are having on non-target animals and its incompatibility with high value, discerning export markets which have increasing animal welfare standards and expectations as well as being risk adverse about poisons (Eason and Jolly, 1993; Parkes and Murphy, 2003; Tompkins and Ramsey, 2007). Aerial 1080 is used to primarily target possums and rats. Land managers often see a flow-on-effect from the reduction to possum numbers to a reduction in stoat numbers. This is because stoats and other scavengers (such as dogs and feral cats) die from secondary poisoning by consuming the carcass of a possum that has died of 1080 poisoning (Ross et al., 
2000). Other non-target animals which are of concern for the public include wild pigs and deer which may accidentally consume the pellets, and trout, which may consume mice poisoned by 1080 (Ross et al., 2000). These non-target animals, although classified as a pest by the Department of Conservation, are valued by the public for recreational hunting and fishing (Parkes and Murphy, 2003; Tompkins and Ramsey, 2007). There has also been concern about native wildlife consuming toxic baits. Native birds are also found dead following 1080 operations although this can be somewhat prevented by different bait designs. For example, discontinuing carrot based bait (Powesland et al, 1999). But due to the tendency of poisons to cause bait shyness and the effect of non-lethal doses on pest populations, poisoning operations often require a secondary follow up operation using a different method such as lethal traps (Parkes and Murphy, 2003).

Lethal traps are another method used to control possum populations (Cowan, 1993). Leg hold traps, kill traps and self-resetting traps are all used in a variety of different contexts (Cowan, 1993; Dix et al., 1997, Glen et al., 2014). However, like poisoning, lethal traps are not an effective method to eradicate possum populations on their own (Cowan. 1993). Trapping is labour intensive and costly. Traps also struggle to eliminate the last few animals of a population. These animals tend to be neophobic and "trap shy" and, therefore, are unlikely to investigate a novel object (such as a trap) in their environment (Cowan, 1993; Warburton and Orchard, 2010). This can be particularly problematic for food-based lures as there are alternative sources of food available, making the lure less attractive (Parkes and Murphy, 2003). This is also the reason that traps will often fail to detect the first few individuals re-colonizing an area after an eradication operation. Food-based lures are also perishable and effective over a relatively short distance (Parkes and Murphy, 2003). 
Biological control has been suggested as an alternative to trapping and poisoning. (Dix et al., 1997; Parkes and Murphy, 2003; Glen et al., 2014). Vaccination, nematodes, bacteria and viruses have all been suggested as vectors to deliver immunological blocks on reproduction (Parkes and Murphy, 2003). Research and trials of these methods have had varying success and there is concern about the design of the delivery system and its ability to be species specific. There is also the possibility natural selection will act on the populations forcing adaptation to any contraceptive agent (Parkes and Murphy, 2003). Consider also that these new technologies and approaches are a long time from application. Further, the public have also voiced their concerns over biological control, leaving poisoning as the preferred method currently (Parkes and Murphy, 2003).

Using the methods mentioned above, many offshore and mainland islands have been able to successfully eradicate their possum populations (Cowan, 1993; Brown et al., 2003). The issue on these islands has now shifted from one of eradication to monitoring and response to re-invasion. Land managers now need to be able to detect new populations at low density or remnant ones at the end of an eradication program. There is a need for long-life lures that are attractive over larger distances especially to reduce the labour of re-visiting self-resetting traps and also might increase trapping success or bait consumption (Parkes and Murphy, 2003).

\section{Semiochemicals and their use in pest control}

Semiochemicals have been suggested as possible lures in pest control since the 1980's as an alternative to polluting insecticide (Levison, 1975; Barclay and Driesche, 1983; El-sayed et al., 2009). One of the key requirements of having an effective semiochemical lure is understanding the animal's behaviour in response to specific 
semiochemicals (Sorensen, 1996). As insect behaviour is highly modulated by semiochemicals the use of these has had the most success in insect pest control (Blum. 1969; Blum and Brand, 1972). For insects, semiochemicals have been used as lures for traps, mass trappings and as reproductive disrupters (Renou and Gurrero et al., 2000; El-sayed et al., 2009).

Since their inception in the 1980's, insect semiochemical lures are now being produced all around the world (Barclay and Driessche, 1983). Insect semiochemical lures have been successful in both mass trapping and eradication programmes (Barclay and Driessche, 1983; El-sayed et al.,2009). Semiochemical lures have led to an increase in horticultural production of up to $50 \%$ in some areas and have successfully eradicated insects such as fruit flies from Hawaii and New Zealand (Elsayed et al., 2009; Renou and Gurrero et al., 2000).

Due to their success with insects (Blum. 1969; Silverstein, 1981; Blum and Brand, 1972; Renou and Gurrero et al., 2000), focus is now turning to how semiochemical lures can be utilised in other species such as mammals (particularly rodents) (Christensen, 1976, Levison, 1975,) and fish (Sorensen and Stacey, 2010). Progress, however, has been slow due to the increase in behaviour complexity in mammals and lack of knowledge about mammalian pheromones (Blum. 1969; Blum and Brand, 1972). Research has been centred on species which cause the most detriment to human activities. Rats, mice (Roberts et al., 2010) and mustelids have all been species of primary concern for researchers. They have also been shown to have been attracted to traps baited with the lures of their conspecifics (Christensen, 1976, Humpheries et al, 1999, Hurst and Beynon, 2004). This has led researchers to believe odours used in scent marking may make the most promising pheromone lures (Goosling, 1982; Goosling and Roberts, 2001). 
To elicit a response from the receiver, a scent mark (such as urine) will have two components. The first, a volatile pheromone to bring the receiver to the scent mark, and a non-volatile pheromone which conveys the information about that individual. Research in mice has shown males will scent mark an area using urine (a common mammalian scent mark) (Christensen, 1976; Goosling and Roberts, 2001, Humpheries et al, 1999, Roberts et al, 2010). Some of the major compounds used in scent marking for mice are major urinary proteins (MUPs) which are non-volatile (Hurst, 1990). MUPs require physical contact with the compound for it to be detected (Humpheries et al, 1999, Roberts et al, 2010). However, some studies have shown mice will still investigate the urine of their conspecifics without having physical contact (Roberts et al, 2010). This kind of response indicates that scent marks (such as urine), and the pheromones associated with them, have the potential to be used in traps for pest control.

\section{Subjects}

The experiments in this study, the first examining the influence of an observer and the second testing the attractiveness of semiochemicals found in the urine of possum, were conducted in a research colony of Australian brushtail possums. In the first experiment to test for an observer effect nine possums in total were used, three females and six males. For the semiochemical tests eight possums were used, two females and six males. The identity, sex, capture location and capture weight of all possums used in this study are described in Table 1. Three of the possums (two male and one female) were provided to the university by Landcare Research Ltd and have been in captivity since 2011, and in our colony since 2014. All other possums were caught from wild populations around the Wellington region (Rimutaka Forest Park, 
Te Kopahu Reserve, Makara and Karori) between December 2014 - January 2015 and also in August 2015.

Each possum was individually housed in a wooden enclosure $\left(1.5 \mathrm{~m}^{2}\right.$ footprint, $2.5 \mathrm{~m}$ in height) with wire mesh $\left(10 \mathrm{~mm}^{2}\right)$ panels on the upper half of the back, right and left side of the enclosures as well as a small mesh window in each enclosure door. The roof of the enclosure was also mesh covered with corrugated weather resistant plastic over top. Possums could see and smell their neighbours through the mesh windows but would not be able to come into physical contact with any other possum, other than through the mesh. 
Table1: Identity, sex, capture location and capture weight of possums used in Observer/Camera trials and Compound trials. Note: possum E-Golden Rosie died in between Observer/Camera Trials. MS= Mt Somners, BP=Banks peninsula, RFP WT= Rimutaka Forest Park Whakanui Track

\begin{tabular}{|c|c|c|c|c|c|c|}
\hline $\begin{array}{l}\text { VUW } \\
\text { ID }\end{array}$ & Name & Sex & Capture Location & Capture Date & $\begin{array}{l}\text { Capture } \\
\text { Weight }\end{array}$ & Notes \\
\hline $\mathbf{E}$ & $\begin{array}{l}\text { Golden } \\
\text { Rosie }\end{array}$ & Female & Landcare Research, MS & $24 / 01 / 2012$ & $1.54 \mathrm{~kg}$ & Died 15/03/2016 from natural causes \\
\hline $\mathbf{H}$ & Hobbes & Male & Landcare Research, BP & $20 / 10 / 2011$ & Unknown & \\
\hline $\mathbf{I}$ & Phillip & Male & Landcare Research, MS & $21 / 10 / 2011$ & $2.65 \mathrm{~kg}$ & \\
\hline $\mathbf{J}$ & Alfie & Male & $\begin{array}{l}\text { RFP WT Wainuiomata } \\
\text { Wellington }\end{array}$ & $6 / 01 / 2015$ & $2.86 \mathrm{~kg}$ & 1-2 years old when caught, good condition \\
\hline $\mathbf{K}$ & Meeko & Male & South Karori Road Wellington & $21 / 01 / 2015$ & $3.21 \mathrm{~kg}$ & 1-2 years old when caught, good condition \\
\hline $\mathbf{M}$ & Beyonce & Female & Te Kopahu Reserve, Wellington & $5 / 03 / 2015$ & $2.61 \mathrm{~kg}$ & Middle aged when caught, good condition \\
\hline $\mathbf{N}$ & Olivia & Female & Te Kopahu Reserve, Wellington & $5 / 03 / 2015$ & $2.21 \mathrm{~kg}$ & 1-2 year old when caught, good condition \\
\hline $\mathbf{O}$ & Samson & Male & Kinnoull Station, Wellington & $22 / 10 / 2015$ & $2.81 \mathrm{~kg}$ & 1-2 years old when caught, good condition \\
\hline $\mathbf{P}$ & Bear & Male & Kinnoull Station, Wellington & $22 / 10 / 2015$ & $2.11 \mathrm{~kg}$ & $\begin{array}{l}\text { 2-3 years old when caught, ok condition, } \\
\text { small for his age }\end{array}$ \\
\hline
\end{tabular}


Each possum was provided with a wooden nest box $(27 \mathrm{~cm} \times 30 \mathrm{~cm} \times 45 \mathrm{~cm})$ and hessian sack $(90 \mathrm{~cm} \times 42 \mathrm{~cm})$ as a refuge and sleeping place (nest). They were free to select either refuge, apart from when they were temporarily locked out of their nest boxes for weighing. Each possum had a continuous supply of water (covered water bucket) and dry possum pellets. Their diet was supplemented by fruit and vegetables, as well as browse collected by research assistants and myself. Browse was provided every 10 days whilst fruit and vegetables were provided when available at a maximum of three times a week.

Possum enclosures were cleaned three times a week (Monday, Wednesday and Friday), at which point their dry pellets were refilled and browse, fruit and vegetables. Water buckets were cleaned twice a week (Monday and Friday). Possum health was also checked, any unusual behaviour (such as activity during daylight hours), injuries, or suspected over-grooming were noted and monitored as required. Over the course of this study, I spent a at least 250 hours on possum husbandry, including training of other research assistants, whole colony enclosure cleaning, live trapping, quarantine, and weighing and urine collection. On weeks where both weighing and urine collection were required, I spent up to 16 hours per week at the colony.

Over the course of this study, six possums were caught from wild populations in the Wellington region. Before any live capture traps were placed in the wild, chew cards were placed along possible routes to detect any possums in the area. If possums were detected, a live capture trap was set, baited with apple or cinnamon paste. The next day the trap was checked, and if a possum had been caught it was brought back to the colony. 
Once a possum had arrived at the colony it was given a medical exam. The possum was placed under a general anaesthetic and antibiotics were administered (one general antibiotic and one specific to bovine Tuberculosis). Age, sex and overall condition was also noted.

Before the possum could join the colony, it underwent two weeks in the quarantine enclosure to ensure that it was not a vector for disease. Inside the quarantine enclosure there were two $1 \mathrm{~m}^{2}$ stainless steel quarantine cages. Each cage had a metal nest box fixed to the front door of the cage as a refuge. When a possum was in quarantine, they were provided with a continuous supply of possum nuts and a water bottle. If a possum was unsuccessful at learning how to use a water bottle, a water container was supplied inside the cage. If fruit vegetables and browse were supplied to the rest of the colony, they were also supplied to possums in quarantine. Each quarantine cage had a mesh floor that would allow urine to drain through onto a tray (lined with newspaper and cat litter) beneath.

Possums in quarantine were cleaned and fed six days a week (MondaySaturday) and weighed weekly to monitor their health. For cleaning, a sliding panel was placed over the nest box entrance, keeping the possum inside whilst the cage was cleaned and food and water replaced. The urine tray was rinsed and replaced. Possums in quarantine were weighed by being locked into the nest box. The nest box was then removed from the quarantine cage, a sack placed over the entrance and the possum was then encouraged to enter the sack. Possums in quarantine were also monitored for any signs of ill-health such as dramatic weight loss and diarrhoea. If either of these two symptoms were detected, the enclosure was cleaned using a Vikron cleaner and supplementary food such as peanut butter sandwiches were 
provided. Only one possum, Olivia, became sick during quarantine, and spent an extra week in quarantine until she had recovered.

When quarantine was being used, the quarantine cages were the last cages of the colony to be cleaned and fed to prevent the spread of any diseases between quarantine and the rest of the colony. All cleaning equipment, food bowls and sacks used in quarantine were kept separate from the other equipment used in the colony. When a possum moved out of quarantine into the colony, the sack used in quarantine was also placed in their enclosure.

Once a month, each possum in the colony was weighed in their hessian sack. To be weighed, the possum was locked out of its nest box overnight with a slider across the entrance, forcing the possum to use the sack as a refuge. Alternatively the possum was placed in the sack by putting the sack over the possum's head and manoeuvring it into the sack. Each possum's weight was monitored during their stay in the colony to as the best indicator of health.

During both experiments in this study, urine was collected from possums in the colony for use in field and laboratory trials. To collect the urine, a possum was manoeuvred into its sack (either by locking the possum out of the nest box the previous day or by placing the sack over the possum's head). The urine collector then held the possum by its tail, whilst the possum was attached to a climbing branch or run, and held a 50ml tube under the cloaca. Any urine expressed by the possum was collected in the tube, pipetted into $1 \mathrm{ml}$ samples and then frozen. A minimum of three samples, collected across three days, were collected per possum.

Over the course of both studies only one possum (female) died (natural causes). We decided not to replace the possum, with one caught from the wild, as 
each possum had to undergo a lengthy quarantine and adjustment period before being able to be used in experiments for this thesis.

\section{Preference experiments in research colonies}

Traditionally, preference or choice and behaviour testing in research colonies has been with rats and mice using a Y-maze (Doty, 1986). This preference testing is not practical in larger laboratory animals like possums (Carey et al., 1997). Preference testing has been conducted in research colonies of possums. Morgan et al. (1995), Todd et al (1998) and Todd et al (2000) tested the attractiveness of various odorous compounds in both the field (Morgan et al., 1995; Carey et al., 1997) and research colony setting (Todd et al., 1998; Todd et al, 2000). All the above studies used a passive method of presentation and all failed to detect a statistically significant difference between compounds. Todd et al. (2000) offered two explanations for this; Firstly, that the environment (colony cages) affected the results and secondly that they were testing odours (such as cinnamon) that the possum may have not encounter in the wild. This is also known as neophobia. In a previous study conducted in the research colony, passive preference testing was used to test the attractiveness of conspecific urine (see Kelly, unpublished honours thesis). As in Morgan et al. (1995), Todd et al (1998) and Todd et al (2000), this study failed to detect a statistically significant difference between the treatment and the controls, although urine tended to have higher rates of interaction compared to the control. As conspecific urine is a substance that the possums would have been exposed to in the wild and is a key component of possum scent marking and olfactory communication it was most likely not neophobia preventing the detection of a statistically significant response. In this study, therefore, I wanted to develop a better protocol for research on the possum colony and apply it to testing semiochemicals on possums. 


\section{Aims}

Due to the destructive effect possums have on New Zealand native flora, fauna and agriculture, as well as the limitations of current pest control methods; there is a need for new long-life lures. These long-life lures must be attractive over long distances and be able to increase trapping success or poison bait consumption. Previous studies have already shown that urine is a candidate lure, and that some of the compounds in urine are positively associated with possum attraction (Linklater, unpublished).

The primary aim of this study was to test whether compounds found in possum urine and food products (that have previously been statistically positively associated with possum attraction and investigation behaviours) were the most attractive. In order to test this I needed to first establish an effective protocol for semiochemical testing in a small research colony of Australian brushtail possums (Chapter two).

As passive presentations in a research colony of possums has not been successful in detecting a difference between treatments and the controls the aim of Chapter two of this thesis was to design a new protocol for in a colony setting. I decided that active presentations were necessary to better illicit a response from possums. To move forward with active presentations, I needed to test what effect my presence would have on the possum's night time activities. I expected that my presence would affect their activity due to a lack of handling during their night-time activities and previous negative handling experiences.

The aim of Chapter three in this thesis was (based of the outcomes of Chapter two) to use an active presentation method to test the attractiveness of urine and food- 
based semiochemicals. I expected that the compounds that are the most attractive would be those that belonged to chemical groups that were known to act as semiochemicals. 


\section{Chapter 2: Testing for an Observer Effect in an Australian brushtail possum colony when behaviour sampling}

\section{Introduction}

Animal behaviour can be quantified directly by observers or recorded for subsequent sampling (Wade et al., 2005). Direct observations and recordings have different advantages and disadvantages. Recordings remove the observer (at least whilst sampling) and can be repetitively viewed. They are, however, prone to technical malfunctions and are more time consuming (Baker and McGuffin, 2007; Iredale et al., 2010). Observers may also influence an animal subject's behaviour particularly by inducing a stress response (Iredale et al., 2010; Leruste et al., 2013).

The influence a human observer has on an animal subject and the subsequent effect on behaviour is known as "The Observer Effect" (Lay et al., 1999). The Observer Effect has been encountered across many disciplines including psychology, the social sciences and biology (Lay et al., 1999). This effect is commonly expressed through changes in the animal subject's physiology and behaviour (Iredale et al., 2010). This can take the form of an avoidance, stress or an attention response (Recarte et al., 1998). It is essential for the response of animal subjects to an observer to be considered by researchers, as the observer effect is both cumulative and reinforcing. An example of this is where observed animals must be handled for other reason there is an adverse reaction by the subject (Rousing \& Waiblinger, 2004). This effect can also be compounded in vulnerable groups (such as juveniles) and in subtle behaviours (such as sexual behaviours) (Lay et al, 1999). In natural environments (and laboratory situations with enclosure sharing) the observer can also influence intra- and interspecific interactions (e.g. predation rates, frequency and outcome of social 
behaviours) (Crofoot et al., 2010). The observer effect is problematic for researchers as the resulting change in animal behaviour could influence the subject's engagement with or reaction to experimental treatments.

An observer effect can be mitigated if animals acclimate or habituate (Recarte et al., 1998). Habituation was defined by Jack et al., (2008) as "the reduction on attention directed towards human observers following repeated neutral contacts".

Habituation is driven through learning (Recarte et al., 1998). Learning occurs through interactions which are predictable, repetitive, localised, and frequent and where interactions can be avoided. (Recarte et al., 1998). Subjects can be considered "habituated" when they no longer respond to the presence of an observer (Leruste et $a l ., 2013)$. When habituation has shown to have occurred, the observer effect may cease to be a problem for researchers (Jack et al, 2008).

Studies on the observer effect have been primarily focused in species, and in contexts where there is high amount of human interactions. Examples of this are zoos (primates) (Crofoot et al, 2010), farms (calves) (Rousing et al, 2005) and conservation programs (passerines) (Mayer-Gross et al, 1997). I could find no examples of the observer effect being studied in animal research colonies. As I was tasked with performing experiments in an animal research colony, it was essential to consider how an observer would or would not influence the animal subject's behaviour to develop an appropriate experimental protocol. Due to the lack of research into the effect of an observer on animal subjects in a laboratory setting it was crucial to determine how an observer may influence animal behaviour in a captive possum colony before behavioural assays of odour compounds could begin. 
From a study done on veal calves, it has been shown animals subjected to handling may change their behaviour towards a human observer based on their previous interactions when handled by the same person (Rousing et al, 2005). In this example, veal calves were less active during the presence of the observer (Rousing et $a l, 2005)$. During daylight hours, the possum colony has been exposed to handling by myself and other research assistants. The possums were fed three times a week, weighed monthly and had urine samples collected from them intermittently. A typical negative (stress) response to weighing or urine collection in the colony was for the possums to screech or climb out of their nest box or sack (Mockett, personal observations). Feeding did not typically elicit a negative (stress) response from the possums and could be considered a positive handling interaction (Rousing et al, 2005; Rousing \& Waiblinger, 2004). Weighing and urine collection were negative handling interactions and reinforced negative responses. Moreover, the possum colony rarely had interactions with humans during their active hours (night time) and so it was essential to understand how they responded to the presence of an observer during those hours as well as to an observer, like me, who they have had both positive and negative handling experiences with.

This study was focused on answering the question; was possum behaviour in the colony effected by the presence of an observer when they were active (sunset to sunrise), and did they change the way they used their enclosure when they were being observed compared to when no observer was present?

Based on previous studies my initial expectation was there would be a difference in the behaviour of the possums when there was an observer compared to when no observer was present. Like the veal calf study (Rousing et al, 2005), I also expected the possums would be less active and use their enclosure differently. This 
could include spending more time at the back of the enclosure as to be as far away from the observer as possible. 


\section{Method}

This study was carried out in a research colony of Australian brushtail possums consisting of nine adult possums (three female and six male) between May and September 2015 and in August 2016.

The colony was cleaned and fed three times a week during this period (as described in Chapter one). Originally there were seven possums in this study, in October 2015 two possums (Bear and Samson) were captured at Kinnoull Station in Wellington and were able to be added to the trial in August 2016. The possums were weighed monthly over the course of the trial to monitor overall health. One possum (Golden Rosie) died of natural causes after this study was completed.

\section{Ethogram}

A behavioural ethogram was created for use in the behaviour analysis program Observer XT (Noldus, 2015). This ethogram was created to measure the duration and frequency of behaviours. Behaviours were chosen based on a previous study of the colonies general behaviour under camera only conditions (Mockett, unpublished). Possums in the colony spent most of their time sitting, grooming and eating. Other behaviours such as scent marking (via chinning or sternal rubbing) and interaction with neighbouring possums also occurred but not at a high enough frequency across enough individuals to warrant being included in this study. The behaviour "interaction" was included to measure the amount of time a possum may spend interacting with the passive presentation of a novel apparatus (treatment). Behaviours examined are listed in Table 2, enclosure use (the amount of time spent in the front and back of the enclosure) was also included in this ethogram. 


\section{Experimental method}

I designed an experiment to measure the effect of my presence, as an observer, on possum behaviour in response to a novel apparatus at the beginning of their nighttime activities. The camera or observer recordings began 30 minutes after sunset (Wellington Daily Forecast, 2016) when possums became active.

Each possum was observed across two nights, one in the presence of an observer (henceforth referred to as "Observer") and the other with only a video camera (henceforth referred to as "Camera").

Treatment order (Observer or Camera) and possum order were chosen under a stratified random design where the treatment order was truly random for each possum but the possum order was modified to prevent the same repeated sequences from occurring across experiment nights. If for any reason a possum's experimental night had to be repeated (due to bad weather or technical failure) that possum was moved to the end of the list and tested again. The first recordings were discarded for one individual in the colony. This only occurred once during the trials.

Two hours before sunset a novel apparatus was set up in the possum's enclosure to represent an experimental device similar to a passive lure presentation. The "experimental device" consisted of a half coconut attached to the back on the enclosure with $20 \mathrm{~cm}$ of $8 \mathrm{~mm}$ diameter rope (Figure 1). The coconut was in the enclosure for two consecutive nights. Every possum had its own coconut and only one possum was observed on any given night.

For both observer and camera recordings a video camera was positioned directly outside the mesh window in the enclosure door on a tripod at a height of 
$1.5 \mathrm{~m}$. Possum behaviour was recorded using a Sony HDR-CX900E Handycam in

Nightshot mode for 30 minutes. On both Observer and Camera nights red LED lights were switched on in the possum enclosures to enhance the quality of filming. These lights were turned on 1 hour and 30 minutes before the experiment was set to start so the lights were on when the possums began to wake. On the Observer nights, I stood outside the enclosure and filmed the possum behaviour for 30 minutes with a with a 5 minute buffer period to eliminate timing error. After the half hour filming period, I left the colony. When the observations ended the red LED lights were turned off. On Camera nights, the camera was set up outside the enclosure and set to beginning 30 minutes before sunset until half an hour after sunset

The video recordings were analysed using the behavioural analysis software Observer XT (Noldous, 2008) with the ethogram in Table 2. For the Observer and Camera videos, the last 30 minutes of video were analysed. Any possum activity in the field of view (whilst the camera was pointed straight ahead), relevant to the ethogram bellow was scored in Observer XT.

Figure 1: The novel apparatus set up in each possum's enclosure for the Observer/Camera experiments.

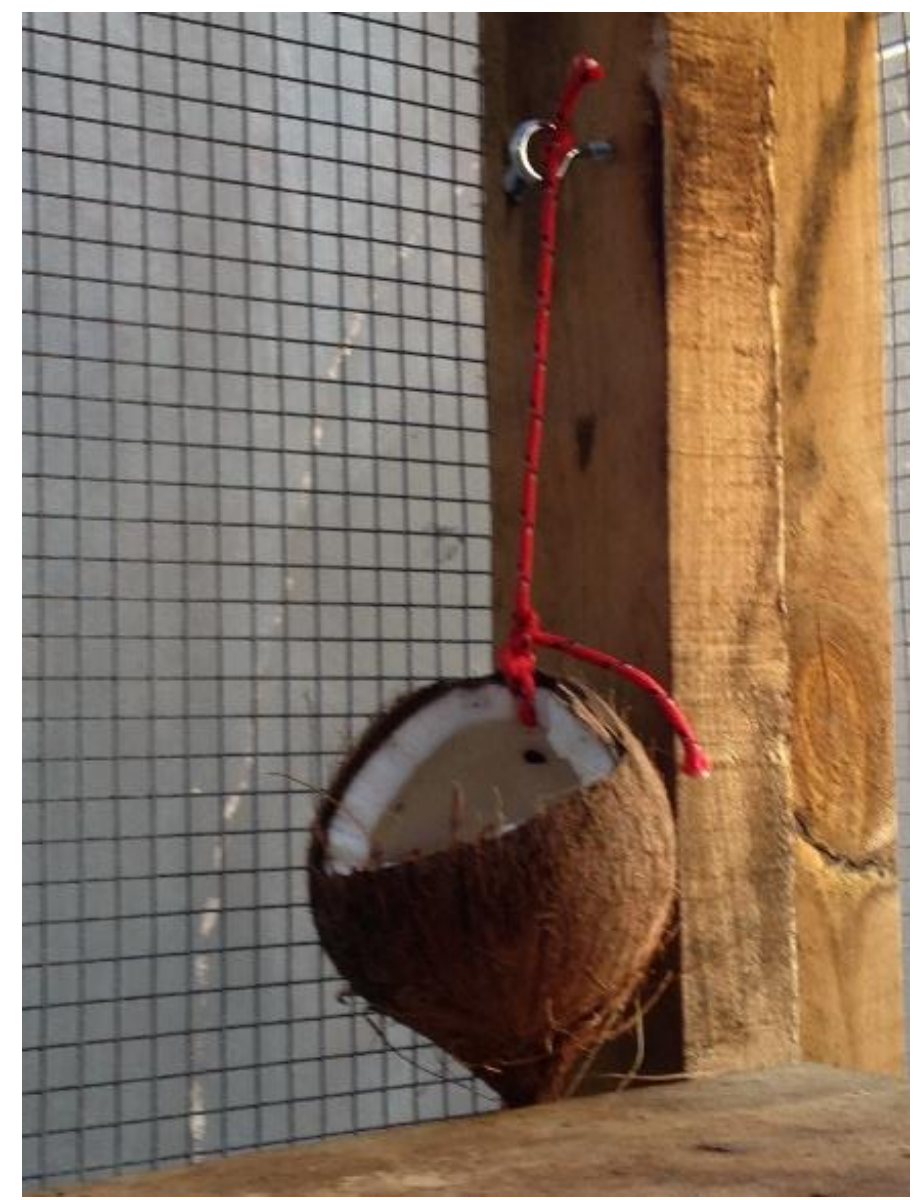




\section{Statistical analysis}

The response variables were; the total duration, mean duration, frequencies of each behaviour and possum location from camera video integration in Observer XT. IBM SPSS Statistics 22 was used to perform a MANOVA of the mean duration of each behaviour for the two experimental conditions (Observer v Camera). The MANOVA was used to detect whether the presence of an observer impacted the behaviour of possums in the colony. The assumption of equal variances in a MANOVA was tested using a Levene's test of equal variances. All data was log transformed in accordance with best practice. A result of $\mathrm{P}<0.05$ was considered statistical evidence of the presence of an observer negatively affecting the behaviour and/or enclosure use of possums. 
Table 2: Observer/Camera ethogram, including the four behaviours and enclosure use

\begin{tabular}{lll}
\hline Behaviour type & Behaviour & Definition \\
\hline Behaviour & Grooming & Maintenance behaviour, licking and /or biting of the individual's fur or body and scratching of \\
the body, limbs or head.
\end{tabular}




\section{Results}

There were a wide range of response to the observer and camera treatments between possums in the colony (see Figure 2a-f) some possums showed little response to either treatment whilst others showed a high level of response.

Some possums were more active than others with, sometimes, large differences between camera and observer treatments. Some possums were more active with an observer present and some without. Eating and Interaction showed no evidence of an observer effect (Figure 2a, 2c) whilst the total duration of time spent Sitting and Grooming (Figure 2b, 2d) increased in the presence of an observer, which might indicate a slight Observer effect. Enclosure use also varied across individuals (Figure 2e, 2f) but there is no clear trend indicating an Observer Effect.

The variation in the response of individual possums across any of the behaviours or use of the enclosure space was not satisfactorily explained by the observer/camera treatments. Across the colony, there was no statistically significant difference in the (average) behaviour of possums between nights in which there was an observer and a camera (MANOVA $\mathrm{F}_{6,9}=0.33, \mathrm{P}=0.90$ ). A Levene's test of equal variances on the log transformed data provided satisfactory evidence that the assumptions of the MANOVA were met $(\mathrm{F} \leq 3.95, \mathrm{p}>0.05)$.

There was no significant difference between the amount of time spent sitting (MANOVA $\left.F_{1}=0.10, P=0.75\right)$, eating $\left(F_{1}=0.28, P=0.61\right)$, grooming $\left(F_{1}=0.43, P=0.52\right)$ or interacting with the apparatus $\left(\mathrm{F}_{1}=0.83, \mathrm{P}=0.38\right)$ between observer and camera nights. 
There was also no significant difference in the average amount of time spent by possums in the front (MANOVA $\left.\mathrm{F}_{1}=0.32, \mathrm{P}=0.58\right)$ and back $\left(\mathrm{F}_{1}=0.32, \mathrm{P}=0.58\right)$ of their enclosures.

Overall the data was highly variable between individuals in the colony. The data was highly variable in both directions as some possums were highly active and others were highly inactive. There was some constancy across the colony (but not statistically significant) for the sitting and grooming behaviours (Figure 2a-f). 

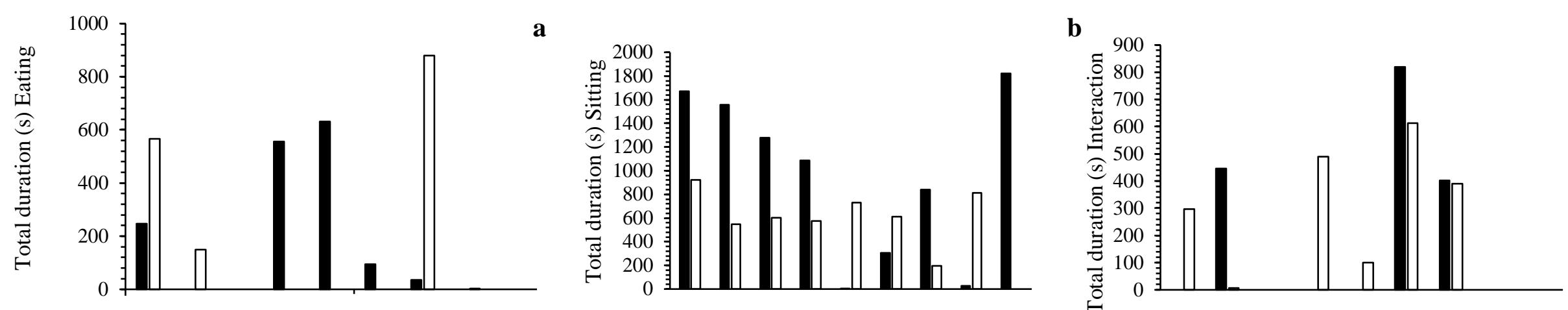

c
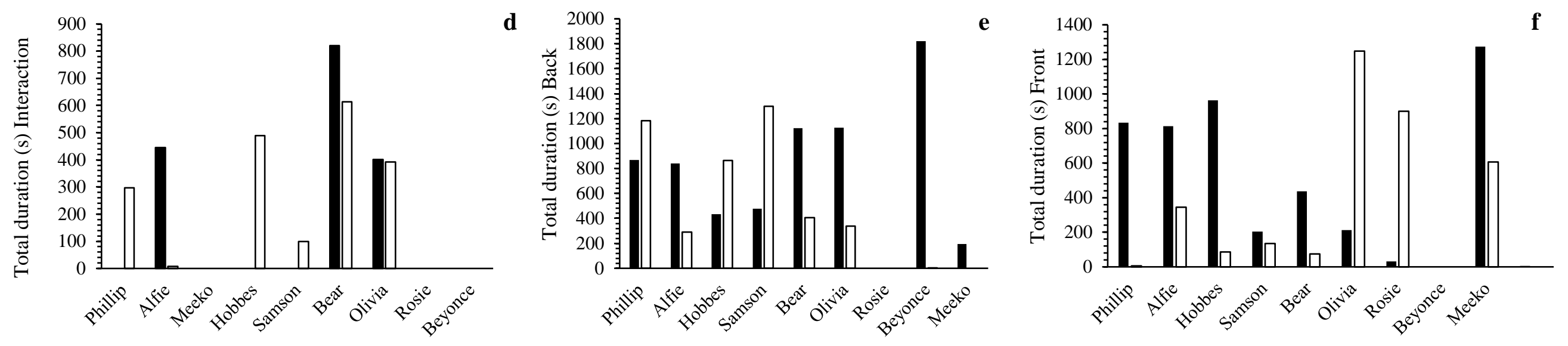

Figure 2: The total duration (seconds) of time spent eating (a), sitting (b), interacting (c), grooming (d), in the back (e) and front (f) for each possum in the colony on observer nights and camera nights. Each data point has a $n=1$ 


\section{Discussion}

The aim of this study was to examine if possum behaviour in the colony was effected by the presence of an observer during their active period (sunset-sunrise) and if the possums changed how they use their enclosure with an observer present compared to no observer being present. Across the colony there were no statistically significant differences detected in any of the behaviours measured (sitting, grooming, eating or interaction), nor was there any statistically significant difference in how the enclosures were used.

It is clear from the data there was a wide amount of variation in the response to an observer between individual animals in the colony. Some were more active with an observer present, and some without. There was an increase in the amount of time spent sitting and grooming within the whole colony when an observer was present. This indicates there may, in fact, be a small observer effect (present in the colony), but the size and severity of this effect is masked by a large amount of individual variation and potentially statistically undetectable due to the small sample (animal) number.

The two behaviours indicated evidence of an observer effect were sitting and grooming. The behaviour "Sitting" is defined as "Inactivity, time spent being still only" in the ethogram (Table 2). "Grooming" is defined as "a maintenance behaviour, licking and/or biting of the individual's fur or body and scratching of the body, limbs or head". An individual may be both sitting and grooming, but as grooming was the active behaviour, it was the behaviour scored. Figure $2 \mathrm{~b}$ and $2 \mathrm{~d}$ show that although it is not statistically significant, in general possums were less active in the presence of the observer. This matches observations made during the observer video recording 
whereby possums would sit in the enclosure and watch me as I filmed them (Mockett, personal observations). These periods of inactivity would often be broken up by grooming. Whilst these behaviours by themselves might not be of concern, an increase in inactivity could have been an indicator of a stress response (Morgan and Tromborg, 2006).

Captivity is inherently stressful on animals which are captured from the wild (Tetley and O'Hara, 2012., 2005; Morgan and Tromborg, 2006). Not only is the capture process stressful, but animals must often undergo transportation, medical checks and quarantine. Each of these have their own inherent stressors (National Research Council, 2008; Morgan and Tromborg, 2006). As described in Chapter one, all possums in the colony were captured from the wild, transported to the colony, underwent a medical exam and quarantine before they were added to the colony. Once in the colony the possums required time to acclimate to the new environment with novel objects (Morgan and Tromborg, 2006). For some of the individuals in the colony, it is possible this would be their first close encounter with humans. All individuals in the colony appeared to eventually acclimatise to interaction with people. Some individuals acclimated quickly, and became relatively docile towards humans. Others took more time, and even after they had been in the colony for over three years, were still aggressive towards humans (Mockett, personal observations).

This acclimatization may be the possum habituating to life in the colony, or they may just not be exhibiting behavioural signs of stress (Balcombe et al., 2004). Under normal colony conditions an individual may not be exhibiting behavioural signs of stress, but may exhibit physiological signs of stress such as weight loss, poor immunity and cessation of reproduction (Tetley and O'Hara, 2012). In our colony weight fluctuated seasonally (lower in winter, higher in summer). They were given 
antibiotics upon arrival to the colony and they were not reproductively active. So, the typical indications of a stress response may not have been detectable in the colony and thus we were unable to determine if the possums have habituated.

Negative handling experiences, such as the monthly weighing and urine sampling, would create negative associations with handlers. These negative experiences can be cumulative and cause a negative association with handlers and observers, the activity or humans in general (Balcombe et al., 2004). As I was the primary researcher doing the monthly weighing and urine collection, there was the opportunity for the possums to develop a negative association with my presence (Balcombe et al., 2004). This negative association could be expressed as inactivity during the observer recordings because the possum was stressed by my presence. By spending more time sitting or grooming the possum was potentially forgoing other activities they would normally do. (Tetley and O'Hara, 2012; Balcombe et al., 2004).

In recent decades, individual variation, also referred to as an animal's personality, has become an accepted, and interesting variable to behavioural ecologists (Carter et al., 2012; Roche et al., 2016). Even laboratory mice, which are bred to behave in a uniform manner (Lewjohann et al., 2011), have been shown to exhibit behavioural differences which cannot be explained by exogenous influences. (Roche et al., 2016; Lewjohann et al., 2011). Previously these behavioural differences have been treated as statistical noise by researchers (Smith and Blumstien, 2008), but it is becoming increasing clear individual variation in behaviour has a profound effect on the welfare, breeding and management of captive animals (Roche et al., 2016; Smith and Blumstien, 2008). In an artificial environment (such as a laboratory or zoo) the animal's responses are to observers are moderated or accentuated by individual personality. (Roche et al., 2016; Tetley and O'Hara, 2012). 
The term "Observer" is not just limited to researchers but can also be applied to visitors, conservationists and the public. Zoos are becoming more interested in how individuals respond to the artificial environment and visitors (Roche et al, 2016; Stoinski et al, 2012). A study done in Atlanta Zoo on the effect of visitor crowd size on the behaviour of Western Lowland Gorillas found the overall crowd size did not influence behaviour. Although some behaviours did show change this was not consistent across their sample (Stoinski et al, 2012). They were, therefore, left to conclude that whilst there was some effect on some individuals this was far from a universal pattern. Similarly, in this study there are indications of an observer effect on some individuals, but this was not consistent across individuals, or even within the same individual across multiple behaviours (Stoinski et al, 2012). Stoinski et al. (2012) hypothesised this inconsistency was driven by both extrinsic and intrinsic factors. One of the extrinsic factors believed to contribute is variability in the exhibit design. In Stoinski et a.l (2012)'s study the population was split into family groups (consistent with wild gorilla behaviour) and each family group was allocated to a different exhibit. Each exhibit was different from the others in terms of size and layout (Stoinski et al., 2012).

In my study possums were housed individually (consistent with wild possum behaviour). Each enclosure was of the same size and dimensions. There were minor differences such as location of the sack and location of climbing branches. But I think the minor nature of these differences would not overly influence behaviour as differences did in the Stoinski et a.l (2012) study. The only major difference between enclosures, which may have influenced behaviour, was what side of the colony they were on. Six of the enclosures were adjacent to a building, whilst three were not. Being adjacent to the building may have offered some protection from weather and 
acted as an additional source of light, as the building was an active lab. Due to the small sample size (six on the building side and three not on the building side) it is not possible to accurately determine what kind of effect this may have had on the possums' behaviour. However, responsive and unresponsive individuals were present on both sides. For example, Beyoncé and Alfie were both on the building side of the colony. Beyoncé was hardly active throughout the trial whilst Alfie was highly active (Figure 2).

In Stoinski et al. (2012), intrinsic factors such as sex and personality were believed to drive the inconsistencies in their study. Male and female gorilla's exhibit sex-based behavioural differences. For example, male gorillas tend to show more aggressive behaviours whereas females are more involved in nest building and grooming. Male and female possums housed individually do not tend to show overall difference in their behaviour (Stoinski et al, 2012). In this study there were only three females which showed vast differences in their behaviour. One "Beyonce' was hardly active throughout the trial whilst another female "Olivia" was (by comparison) quite active. Similarly, in the males, there was a wide range of activity patterns, from highly active (Phillip), to hardly any activity (Samson). Once again, due to the sample size I was unable to examine how sex would affect the response of possums to an observer. Due to the wide variation across and between the sexes, however, it is more likely individual variation is responsible for most variation is in the data.

A common issue amongst animal behaviour studies is small sample size. In contexts where, for various reasons, the sample size is small researchers greatly limit their statistical power (Cleasby et al., 2015; Smith and Blumstien, 2008). Perhaps this is the reason why in the past individual variation was considered as statistical noise by researchers (Cleasby et al., 2015). My study did have a small sample size, due to 
constraints on the accommodation availability for the colony. The trends in our data indicate there may be evidence for an observer effect in the colony (at least for some behaviours and some individuals) however I did not have sufficient sample size for this to be detected by the statistical tests (Cleasby et al., 2015; Smith and Blumstien, 2008; Stoinski et al., 2012).

Two behaviours out of those analysed, sitting and grooming, indicated a slight observer effect. These behaviours are inactive behaviours which saw a slight increase under the presence of an observer. An increase in these behaviours could be indicative of a stress response to the presence of an observer. However, a small sample size and large amount of individual variation make it difficult to discern if the observer was the cause of this trend. Future studies could have repeated this experiment more than once for each possum but, more powerfully, have a larger sample size of animals to determine the exact effect of an observer on a colony of captive possums.

In this study, there was evidence that inactivity was increased in the presence of an observer but there was no indication that the possums avoided the observer by spending more time in the back of the enclosure. However, a behaviour was only scored if it was within the field of view of the camera. As possums moved about during the filming process they did frequently move out of view. Areas of the enclosure which were out of view were the floor of the enclosure, the left and right front corners, above the door frame and inside the sack or nest box. It is possible that the possum avoided the observer by moving out of the camera view.

This study was required to take place in a research colony environment. It would have been logistically extremely difficult to perform an observer experiment in the wild (Walton and Toth, 2016). This is due to the natural biology of the possum 
and how possum populations are managed in the Wellington region (Parkes and Murphy, 2003). In the wild, possums roam throughout their home range, taking twothree nights to cover their entire range (Cowan and Clout, 2000). They also have multiple den sites across their home range which they will alternate between. This means the home range of a local population of possums can cover several kilometres (Cowan and Clout, 2000). Possums are also under extensive population management by the Wellington Regional Council and the Department of Conservation, meaning possum populations are suppressed in most areas (Parkes and Murphy, 2003). This would have meant conducting this study, and the ability to conduct any subsequent studies in the wild (whilst it would be ideal), would be incredibly difficult. There would be no guarantee possums would be attracted to the experiment as the experiment may not be located in the same part of their home range. Also, it is difficult to identify specific individuals in the wild from video recordings. Thus, we could not be certain whether multiple individuals were coming to investigate the site, or it was the same individual(s) (Walton and Toth, 2016).

From this study, I can conclude the presence of an observer may influence the behaviour of some individuals in a research colony of Australian brushtail possums. Although my results were not statistically significant, there are trends in the data for and observer effect some behaviours (Fig $2 \mathrm{~b}$ and $2 \mathrm{~d}$ ). In the presence of an observer, animals in the colony did tend to spend more time being inactive. This could be indicative of habituation or a stress response. However, there is a lot of individual variation in the data from large amounts of inactivity to larger amounts of activity. It could be more beneficial if a future study could expand the sample size to more individuals across a variety of nights to get a better understanding of how an observer may influence the behaviour of possums in a small research colony. These results 
however were satisfactory enough that I felt the impact of my presence on the colony during their nightly activities would be minimal and we could successfully move forward with the next stage of the single odour compound presentations. 


\section{Chapter 3: Testing the behavioural response of Australian brushtail possums to semiochemicals found in possum urine and food products}

\section{Introduction}

Olfactory communication is an important method of communication in marsupials (Salamon et al., 1999). Most olfactory communication occurs through scent marking. An individual will leave its scent on the environment to communicate to others information about their condition, dominance and breeding availability. An individual's scent can be left on the environment through urine, faeces, or via the products of various glands (Salamon et al., 1999). In marsupials, these glands are located on the chin, sternum, pouch and cloacal region (Salamon et al., 1999). Secretions from these glands can be left on the environment either passively or actively by rubbing the chin, sternum or cloaca on objects (Salamon et al., 1999).

In the Australian brushtail possum (Trichosurus vulpecula), important glands for scent marking are found on the chin and sternum (Mclean, 2014). Both sternum and cloacal glands are the same in males and females (Mclean, 2014). Analysis on the secretions of the sternum gland of possums show they secrete a mixture of fatty acids, heterocyclics, phenolics and aldehydes but most compounds are waxy esters (thought to be cholesterol esters of $\mathrm{C}_{16}$ and $\mathrm{C}_{18}$ fatty acids). The importance of the cloacal glands in scent marking by the possum is unclear. Possums have two glands in the cloaca region, a larger oil secreting holocrine gland and a smaller apocrine cell secreting gland (Mclean, 2014). It is believed that the holocrine gland plays a role in chemical communication for the possum as its secretions are quite odorous (Mclean, 2014). The apocrine gland does not appear to have any significant odour and it is unclear what they purpose of the cell secretions are (Mclean, 2014). 
Previous research on the chemistry and function of the gland secretions in possum olfactory communication is severely limited. Woodhouse et al., (1994) performed a chemical analysis on the sternal gland and the cloacal holocrine and apocrine glands secretions. Woodhouse et al., (1994) managed to identify fatty acids and lipids within these glands. Woodhouse et al., (1994) also proposed that there was no difference in the composition of the gland secretions between the sexes based on the observed compositional similarities. Woodhouse et al., (1994) presented gland materials to possums in their research colony and found no significant behavioural change, leading them to conclude that it was not the chemical signature of the secretions that were important, but rather the bacterial decomposition of the secretions which elicited a response. This was supported by the finding of bacteria in the glands. The fatty acids found in the holocrine gland are uncommon in the animal world (similar compounds can be found in male goats and the marking secretions of tigers) and it may be possible that olfactory communication is achieved through a cocktail of compounds (Mclean, 2014).

Mclean et al., (2012) expanded on the research conducted by Woodhouse $e t$ al., (1994) by conducting GC-MS analysis on swabs from the cloacal region of the possum. McLean et al (2012)'s analysis showed there were many different semiochemicals found in the cloacal glands. Acids, alcohols, decyl esters, formate esters, sulfur compounds and alkylglycerol ethers were all found in the cloacal swabs. It is acknowledged by McLean et al (2012) that they did not explore the source of the compounds and they assumed the compounds came from a variety of sources including urine, faeces as well as the cloacal glands. The compounds of most interest are the acids and alcohols group as these have been known to act as pheromones. It is 
these compounds which have are most likely to be used in possum olfactory communication (Mclean et al, 2012).

A previous study conducted in our research colony has shown possums do respond and investigate the urine of other possums (Kelly, unpublished honours thesis). However due to a small sample size the results were weak. Before the work done in our research colony, preference testing in possums has been severely limited. A study conducted by Todd et al., (2000) conducted preference testing in a possum research colony. Their method involved passive presentation of food products. Whilst they were successful in their study, passive presentations have proven to be difficult in a colony such as ours. Todd et al., (2000) had small un-enriched cages whereas our possums were housed in larger enclosures with provided enrichment.

In previous urine trials, passive presentations had been somewhat effective, however there was a lack of engagement on some of their experimental nights which we felt could be improved upon (Kelly, unpublished honours thesis). Field studies conducted in wild populations of possums supported the research colony study by showing that possum was also attracted to traps with urine lures (Linklater, unpublished). For this study, it was concluded we may have better success if active presentations were used. This was based upon a study conducted by Charlton (2014). This study testing the attractiveness of conspecific urine on koalas. The aim of this study was to identify which semiochemicals, which have previously been identified as being positively associated with possum attraction, were more attractive than their controls and a standard lure. I hypothesised that those semiochemicals which would be most attractive are those found in the acids/alcohol group as predicted by McLean et al. (2012). 


\section{Methods}

\section{Subjects}

This study was conducted on a maintained colony of possums consisting of eight adult possums (two females and six male) between April and October 2016.

The colony was cleaned and fed three times a week during this period (as described in Chapter One). During this period, possums were weighed monthly and urine was also collected at intermittent intervals.

\section{Compounds}

Sixteen semiochemicals in total were tested on the possum colony as well as three control substances (coconut oil, dimethylformamide (henceforth referred to as DMF) and ethanol) and one standard lure (cinnamon paste) (see Table 3). Twelve compounds were derived from possum urine and were suspended in artificial urine containing either ethanol or DMF. The artificial urine also contained creatine, urea, sodium, potassium and chloride. Three compounds were derived from food products (Teripinen-4-ol, Methyl 2-methylbutate and Acetone) and suspended in fractionated coconut oil. All urine and food based semiochemicals were suspended in their respective controls via serial dilution to the concentrations found in Table 3 . The 12 urine-based semiochemicals were selected from sample GC-MS analysis of urine taken from possums in the colony. Urine derived semiochemicals and controls were frozen in $1.0 \mathrm{ml}$ samples, food derived semiochemicals and control compounds were refrigerated in $1.0 \mathrm{ml}$ samples. Two tablespoons of the cinnamon paste were stored in an airtight sample jar at room temperature. 
A behavioural ethogram was created for use in the behaviour analysis program Observer XT (Table 4) (Noldous, 2008). This ethogram was created to measure the duration and frequency of possum interaction with the compounds, standard and controls. Behaviours were chosen based on the results from a previous study of field experiments in a wild population.

\section{Experimental method}

The semiochemicals were split into two trial subsets. The first consisted of six compounds and two controls (ethanol and DMF) and the standard lure (cinnamon paste). This experimental set was run between April and May 2016. The second subset consisted of all four controls, the three food-derived compounds and the six urine derived compounds and ran between October and November 2016.

During each experiment night, each possum was presented with only one compound. Each night each possum received a different compound until all the possums had received all the compounds once. The order the possums received the compounds in and the order each compound was presented to each possum was done using a stratified random design. At least one full day and night past between each experiment night. On an experiment night, compounds were removed from the fridge or freezer and left to acclimatise to room temperature for two hours before the start of the experiment. The experiment began one hour after sunset (Wellington Daily Forecast, 2016).

To present the semiochemicals, standard and controls to possums a lab swab was fixed to the end of a $1.2 \mathrm{~m} \times 6 \mathrm{~mm}$ untreated pine dowel and then dipped in the compound for three seconds. Ten centimetres of $6 \mathrm{~mm}$ clear vinyl tubing was then put 
over the swab to prevent the possum coming into direct physical contact with the compound. The vinyl tubing was secured to the dowel with masking tape. The compound was then presented to the possum through one of the $10 \mathrm{~mm}$ gaps in the mesh window of the enclosure. The end of the swab was pushed through the enclosure until it was just out of arms-reach of the possum. The possum's behaviour in response to the swab was recorded for three minutes with a Sony HDR-CX900E Handycam in Night shot mode. Once the presentation of the compound was completed the dowel was removed from the enclosure. Both swab and vinyl tubing were discarded after each use.

The video recordings were analysed using the behavioural analysis software Observer XT with the ethogram in Table 3. Recording began when the compound was half way into the enclosure.

\section{Statistical Analysis}

The response variable, total duration, mean duration and frequencies of each behaviour from camera video recordings were generated in Observer XT. IBM SPSS Statistics 22 was used to perform a MANOVA of the total duration of each of the three behaviours for each compound. A Levene's test of equal variances was performed with the log transformed data, to test the assumptions of the MANOVA. Failing to meet the assumptions, a Kruskal -Wallis test was performed for each behaviour. To control for the wide amount of individual variation in the colony, a Kruskal-Wallis test was also performed on the difference in behaviour between the treatment and control. The control data used was relative to what type of substance the semiochemical was suspended in (ethanol, DMF or coconut oil) and was relative to each possum. A result of $\mathrm{p}<0.05$ was considered statistical evidence of the 
compound being statistically different from the controls and thus a reference for that behaviour. 
Table 3: Identity and concentration of all urine and food-based semiochemicals, controls and standard lure used in semiochemical experiment

\begin{tabular}{|c|c|c|}
\hline Compound & Unique ID & Concentration \\
\hline 2-Butanone & 804 & $463 \mathrm{ppb}$ \\
\hline $\begin{array}{l}\text { Propane, 2-ethoxy-2-methyl-/tert butyl } \\
\text { ethyl ether }\end{array}$ & 805 & $156 \mathrm{ppb}$ \\
\hline Butanal, 3-methyl- / Isovaleraldehyde & 809 & $17 \mathrm{ppb}$ \\
\hline 2-Pentanone, 4,4-dimethyl- & 842 & $246 \mathrm{ppt}$ \\
\hline Phenol & 976 & $8 \mathrm{ppm}$ \\
\hline Phenol, 3-methyl- & 1069 & $31 \mathrm{ppm}$ \\
\hline $\begin{array}{l}\text { artificial urine with ethanol at same conc as } \\
\text { in samples }\end{array}$ & E (control) & 0.736111 \\
\hline $\begin{array}{l}\text { artificial urine with DMF at same conc as } \\
\text { in sample }\end{array}$ & D (control) & 0.736777 \\
\hline Cinnamon paste control & $\mathrm{CP}$ (reference) & $\begin{array}{l}\text { Commercially available sample, Good Nature Possum Cinnamon } \\
\text { Formula }\end{array}$ \\
\hline 1-Butanol, 2-methyl-, acetate & $892 \mathrm{~A}$ & $13 \mathrm{ppt}$ \\
\hline Phenol, 4-ethyl- & 1162 & $6 \mathrm{ppm}$ \\
\hline Styrene & 902 & $30 \mathrm{ppm}$ \\
\hline Butanenitrile, 2-methyl- & 823 & $8 \mathrm{ppb}$ \\
\hline $\begin{array}{l}\text { Propane, 1-(1,1-dimethylethoxy)-2-methyl- } \\
\text { /1-(tert butoxy)-2-methylpropane }\end{array}$ & 834 & $160 \mathrm{ppb}$ \\
\hline Acetone & $\mathrm{C}$ & $0.01 \mathrm{ppm}$ \\
\hline Teripinen-4-ol & A & $0.01 \mathrm{ppm}$ \\
\hline Methyl 2-methylbutyrate & $\mathrm{B}$ & $0.01 \mathrm{ppm}$ \\
\hline Coconut oil & $\mathrm{CO}$ (control) & Fractionated coconut oil/medium chain triglyceride \\
\hline
\end{tabular}


Table 4: Ethogram for semiochemical experiment analysis

\section{Behaviour Behaviour Definition}

type

Behaviour Latency to The time taken for the possum to come within one head length of the end of the swab
approach

Sniff Olfactory engagement of the swab. Characterised by obvious sniffing motion with the

head

Grab

Grasping of the swab with either of the two front paws of the possum. 


\section{Results}

There was large variation across the animals in the colony, not just in how each possum responds to individual compounds, but also in levels of activity between possums. Some possums were largely inactive and took a long time to approach the compounds, if they approached them at all (Figure 3a). Whilst others quickly approached compounds and interacted with most of them (Figure 3b), some more so than others. These trends were not consistent between sexes, however, with the two females in the colony showing two different levels of interaction. Figure $3 \mathrm{~b}$ shows a female which quickly approached and interacted with the compounds whilst Figure $3 c$ shows a female which took a long time to approach compounds, if they were approached at all and she rarely interacted with them.

The Machauly's test of spherity showed the data breached the assumption of spherity (Greenhouse-Geisser $\mathrm{F}_{1}=148.230, \mathrm{P}>0.0001$ ) required for a repeated measures ANOVA. A Levene's test of homogeneity revealed the data did not provide satisfactory evidence that the assumptions of the MANOVA were met for any of measured behaviours (MANOVA $\mathrm{F}_{18}<3.534, \mathrm{P}<0.05$ ).

A non-parametric test concluded there was no significant difference between the compounds and their control for time to approach (Kruskal-Wallis Chi-squared $\mathrm{df}=16=14.073 \mathrm{P}=0.59)$, sniff (Kruskal-Wallis Chi-squared $\mathrm{df}=16=22.414)$ or grab (Kruskal-Wallis Chi squared $\left._{\mathrm{df}=16}=11.394, \mathrm{P}=0.79\right)^{\text {) }}$

Most of the compounds presented to the colony were approached faster than their respective controls (Figure 4a), or grabbed and held for longer (Figure 4c), and a few were investigated by sniffing for longer (Figure 4c) but only a few were statistically different from the controls, and only for one or two of the behaviours. 
Nonetheless, the semiochemicals 804,805 976, 1069, 1069A and 834 received a stronger response than controls.

Figure 5 a-c shows the mean time to approach, time spent sniffing and time spent grabbing. Across the colony 11 compounds $(804,805,809,976,1069,1069$ A, 892A, 1162, 823, 834 and C) were approached faster than the standard (Figure 5a) (cinnamon paste), but only two compounds, (804 and 805) were sniffed longer than the standard (Fig 5b). Six compounds (805, 1069,892A, 1162,823, and 834) were grabbed for longer than the standard (Fig 5c). 

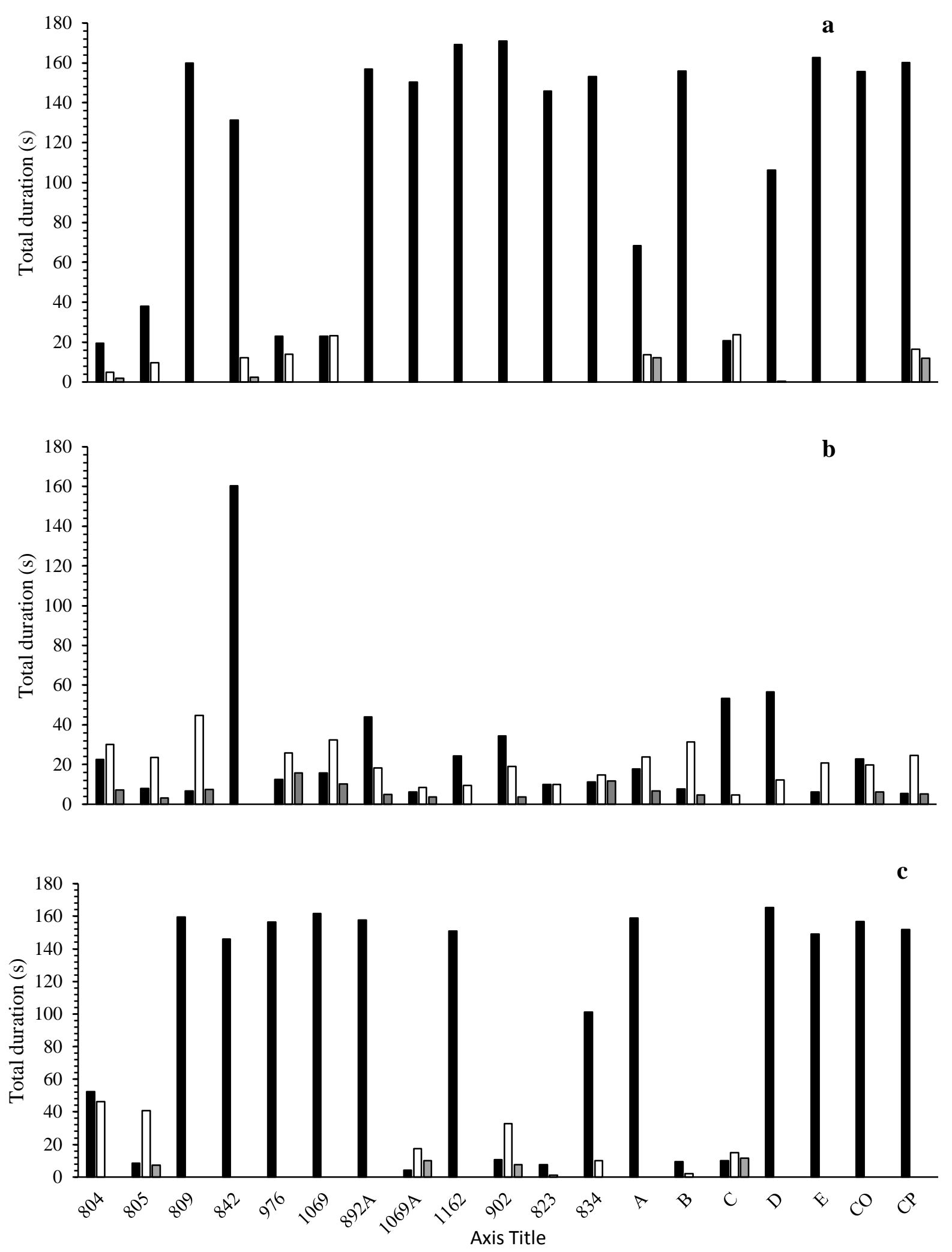

Figure 3: Total duration of time to approach (black), sniff (white) and grab (grey) for three possums in the colony a. Samson (male), b. Olivia (female) and Beyoncé (Female) for all compounds, controls and standard. 

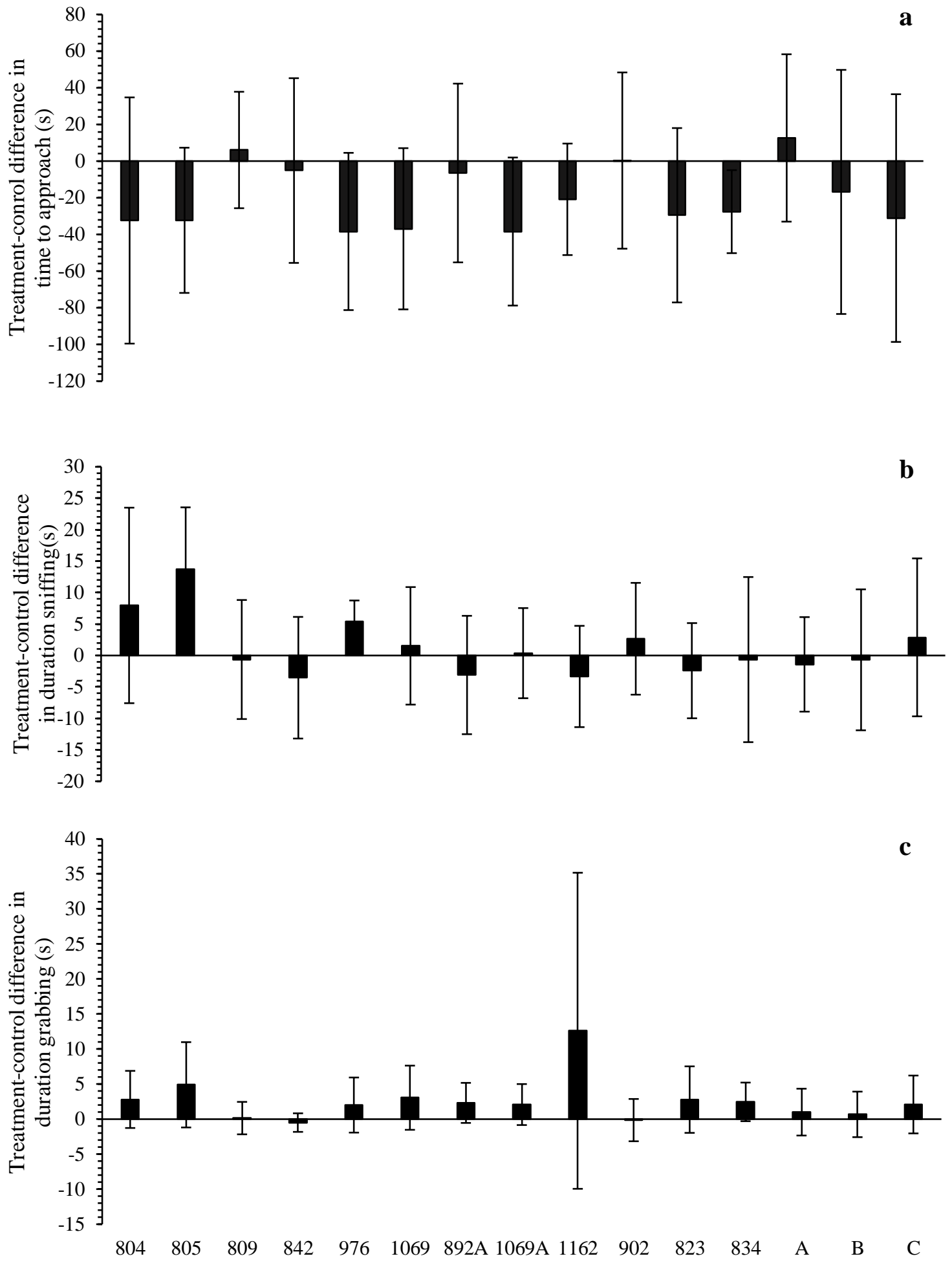

Figure 4. The mean difference between the treatment and its control (seconds) of time to approach (a), sniffing(b) and grabbing (c) of urine based (804-834) and food based compounds $(\mathrm{A}, \mathrm{B}, \mathrm{C})$ for the colony $(+/-95 \% \mathrm{CI})$. Each compound has $\mathrm{n}=8$. Key to compounds in Table 3 

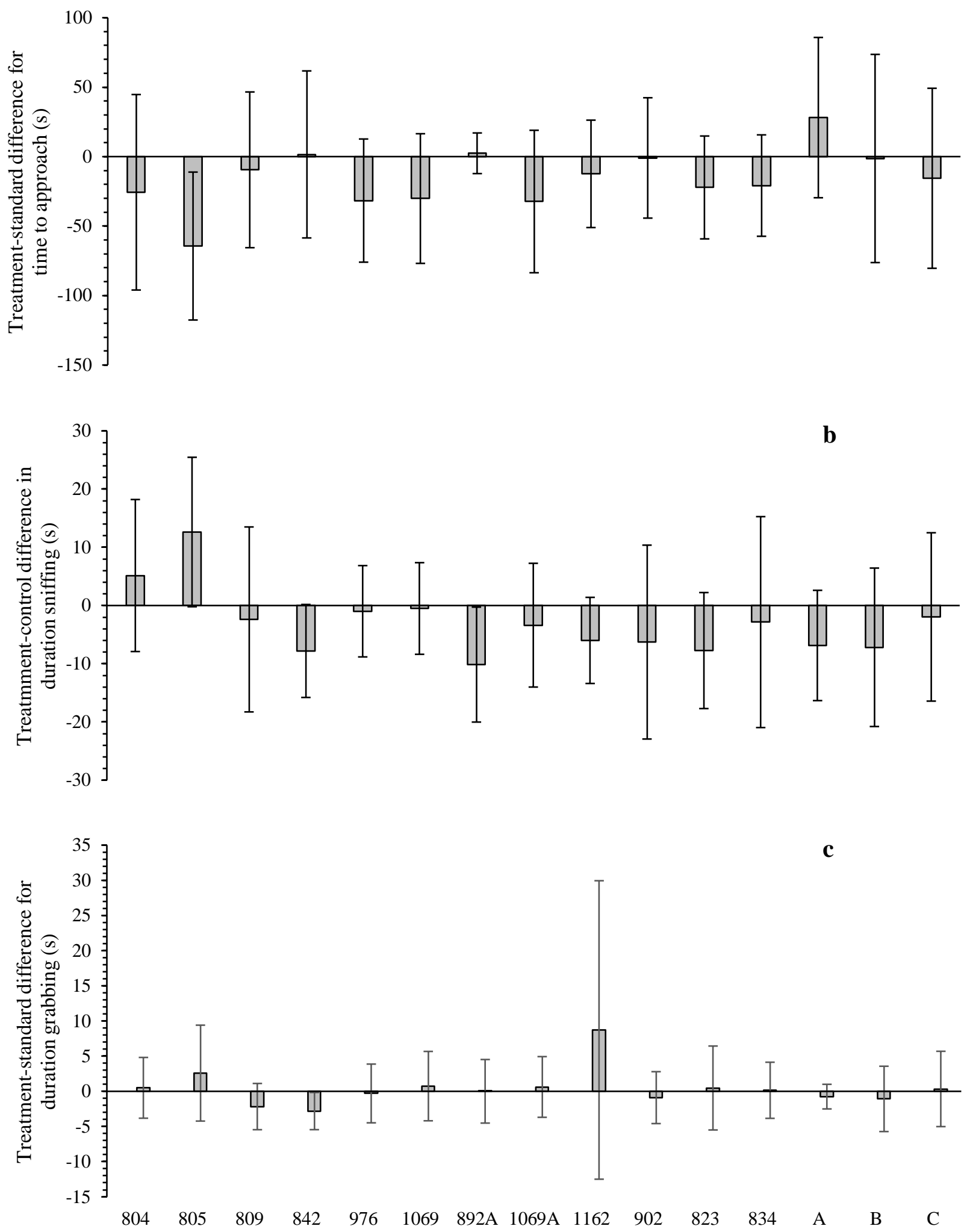

Figure 5: The mean difference between the treatment and the standard (seconds) of time to approach (a), sniffing(b) and grabbing (c) of urine based (804-834) and food based compounds $(\mathrm{A}, \mathrm{B}, \mathrm{C})$ for the colony $(+/-95 \% \mathrm{CI})$. Each compound has $\mathrm{n}=8$. 


\section{Discussion}

There were a wide range of responses across the colony to the semiochemicals. Possums varied in which compounds they responded to, how they responded and the magnitude of that response. As shown in Figure 3 a-c some animals were highly responsive to compounds and readily interacted with them whilst others rarely engaged. This is most likely due to individual variation between members of the colony. Previous research using this colony has shown there is a high amount of variation in the response of individuals which cannot be explained by other variables such as sex (as illustrated in Fig 3a and 3c, see chapter 2). However, this colony is biased towards males, so it is possible there is a sex difference in the response (Stoinski et al., 2012) however it just couldn't be detected in this study.

I found no consistent attraction or investigation (sniff or grab) response by possums to all the 16 semiochemicals tested. However, some semiochemicals showed statistically significant different responses compared to the control or standard lure for one or two of the three behaviours measured. In terms of time to approach, most semiochemicals did better than the reference which was a commercially available cinnamon paste. However out of those, only six outperformed their controls. For time spent sniffing, only two compounds (2-Butanone and tert-butyl-ethyl ether) outperformed both their controls (Figure 4a-c) and the standard (Figure 5a-c). Most of the semiochemicals which out-performed the standard, also out preformed their controls for time spend grabbing.

Out of the original 16 semiochemicals tested, five out-performed both the standard and their control in at least two of the behaviours measured (2-Butanone, tert-butyl-ethyl ether, Phenol, 3-methyl-phenol, and Acetone). Two compounds 2Butanone and tert-butyl-ethyl ether were more attractive than both the standard and 
the control in all three behaviours measured. It indicates there are compounds within possum urine with the potential to be more attractive lures than what is currently being used by land managers.

The compounds 2-Butanone and Acetone are ketones. The two most attractive compounds (2-Butanone, tert-butyl-ethyl ether), listed above, are volatile compounds. These have been found to act as compounds in a wide variety of animals (Mclean, 2014). Ketones act as sex pheromones in male-male interactions in cockroaches (Nauphoeta cinerea) (Moore et al., 1995), an aggregation pheromone in flies (Moats et al.,1987; Hong Tan et al.,2014) and sex pheromones (female-male and malefemale) in garter snakes (Thamnophis sirtalis) (Mason et al., 1989; Lemaster and Mason, 2002) and the white spotted longicorn beetle (Anoplophora malasiaca) (Yasui et al., 2003; Miller et al.,2011). Alcohols such as tert-butyl-ethyl ether are also used as pheromones in a variety of animals (Heath et al., 1992). Phenols are used as sex pheromones and aggregation pheromones (Moats et al., 1987; Torto et al., 1994; Whittle et al.,2000).

It is unsurprising the compounds which were most attractive to the colony are volatile compounds which also act as sex pheromones in other animals (Witzgall et al., 2010; Mclean, 2014). It is possible these compounds are used as sex pheromones in the possum (Witzgall et al., 2010). As possums are solitary animals they require volatile compounds to communicate to members of their own sex as well as the opposite sex (Salamon et al., 1999).

Semiochemicals are used by most animals to attract and communicate with members of the opposite sex (Lemaster and Mason, 2002). For females, they can be used to signify that a female has come in oestrus and is ready to mate (Yasui et al., 
2003). Males will use semiochemicals to communicate to females that they are the best mate choice (Lemaster and Mason, 2002). They can also be used to communicate dominance to other males who may come into the male's home range looking for females (Lemaster and Mason, 2002). A male can then decide to contest dominance or they may decide to actively avoid the more dominant individual (Salamon et al., 1999). My results indicate that some of the semiochemicals tested may function in these ways.

The most severe limitation in this study was the sample size. Due to the space constraints in the colony it was not possible to have a sample size bigger than nine at any one time (although for this study we had a sample size of eight). Due to time constraints, it would not have been possible to continuously replace individuals during the period of this study as catching wild possums from local populations are labour intensive and time-costly as they have to undergo quarantine (as described in Chapter one).

It is also possible that a research colony may not be the best environment for preference testing (Todd et al., 2000). The amount of researcher effort, small sample size and tendency of animals to be less responsive in a small enclosure space do suggest that a small research colony may not be the most efficient method of semiochemical testing. Field studies conducted in the Wellington region using the same compounds (at the same concentrations) have generated clearer results with a larger sample size over a shorter time (Merz, unpublished)

Five compounds 2-Butanone, tert-butyl-ethyl ether, Phenol, 3-methyl-phenol, and Acetone) out-performed their controls and the standard lure in at least two of the behaviours measured. These compounds belong to the ketone, alcohol and phenol 
chemical groups which all act as pheromones in other species. This supports my hypothesis that the most attractive compounds would belong to chemical groups that contain pheromones. The lack of statistical significance in this study could be due to the sample size, high amount of individual variation or the research colony environment being unsuitable. Future studies may consider increasing colony size or cycle through individuals to increase statistical power (Stoinski et al., 2012) and reduce individual variation or move directly to field trials (Todd et al.,2000; Merz, unpublished). 


\section{Chapter 4: General Discussion}

The aim of this thesis was to investigate the effect an observer may have on a research colony of Australian brushtail possums and then to use that information to construct a new protocol for testing the attractiveness of compounds derived from possum urine and food products against their controls and a commercially available reference.

The intention of the first experiment, the Observer vs Camera experiment, was to inform the methodology for the second (compound experiment). Previous experimental work in the research colony used passive presentations (see Kelly, unpublished for a description of methods). These passive presentations were not successful. Nonetheless, they did provide us with enough evidence to conclude that possums did respond to the urine of their conspecifics. Thus, there was a need to develop a better methodology for testing semiochemicals in the research colony.

Before this study, odour preference testing in possums had been conducted in both the field and the laboratory. In the field, Morgan et al (1995) tested the attractiveness of various food products for cyanide bait stations. In the lab, Morgan et al (1995), Todd et al (1998) tested odour preferences of different compounds in a caged environment. All the above studies failed to detect a significant difference between compounds. Todd et al (2000) suggested two reasons for this, firstly, the environment in which the bioassay is conducted may affect the results obtained and secondly, they were testing odours that the possum may not have come into contact with in the wild. Todd et al (2000) attempted to control for these factors in a laboratory experiment but still failed to detect a significant difference between compounds. The reason for this failure could in fact be that the compounds truly 
weren't more attractive to possums than their control. But it is also possible that the passive presentation method failed to discriminate between compounds in captive conditions.

From previous work in the colony, we know that possums do respond to urine (Kelly, unpublished honours thesis), but this result was not statistically significant. So, perhaps, an active presentation technique would be able to detect a statistically significant result. A study conducted with captive Koala's using an active presentation method was relatively successful (Charlton, 2014). However, it has been noted in captive animals that observers can also influence the behaviour of the animal subject. As an active presentation, would require me to be present, it was essential to understand how my presence would influence the behaviour of possums in the colony.

\section{Observer Effect and study design}

Animals make associations between positive and negative experiences and the causes of those experience (Recarte et al., 1998). In the context of the colony, the possums have had both negative (weighing and urine collection) and positive (feeding) with me as a researcher. These negative and positive handling experiences are cumulative and reinforcing (Recarte et al., 1998). Previous studies into the observer effect have shown a decrease in activity in species affected by an observer (Rousing et al, 2005). There may also be an increase in undesirable activities such as aggression. Whilst the colony is acclimatised to interactions (whether they are positive or negative) during their inactive hours (daylight) they are not used to any interactions during their active hours (night time) when the compound experiment would be taking place. Therefore, I would expect that there would be an observer 
effect on the colony, and this would be exhibited through a reduction in activity when the observer was present, compared to when the observer was absent.

Across the colony, I could detect no observer effect. However, there was a wide amount of individual variation in the response to an observer across the colony. Some individuals showed a large difference in their behaviour in the presence of an observer compared to their behaviour without an observer. Others showed a low level of activity overall and there was not much difference between their behaviour on Observer nights and Camera nights. There could be multiple reasons for this. The simplest and most likely is that there is individual variation between animals which leads to some (generally) being more active than others. In the past, individual variation has just been classified as statistical noise by researchers (Smith and Blumstien, 2008). But it is becoming increasingly clear that individual variation, especially in a small data sets, is a naturally occurring variable which behavioural ecologists need to consider when they are conducting bioassays (Smith and Blumstien, 2008).

Individual variation is especially prevalent in research colonies whose animal subjects are sourced from the wild (such as this research colony was). It is very difficult to eliminate this variation (and its subsequent effect) (Balcombe et al., 2004). Even lab mice and rats which are selectively bread for uniform behaviour still show a significant amount of individual variation in their behaviour and response to experimental treatments (Lewjohann et al., 2011). Perhaps, individual variation is then something that can be controlled or allowed for in the experiment protocols especially by increasing sample size (Lewjohann et al, 2011). A small sample size is a problem many animal behavioural bioassays have as researchers are typically limited by the availability of animals and space (Stoinski et al, 2012). Where possible, to 
overcome a large amount of individual variation in a small colony study, it may be beneficial to cycle through animals and replicate within an individual (i.e. repeated measures). In this study, there were constraints on colony size which limited the study to nine possums. If the capture and quarantine protocols had allowed it may have been beneficial to also actively live trap new animals and bring them into the colony for shorter periods. However, the live trapping and quarantine of new animals is labour intensive. And therefore, it was impractical to expand the sample size in the given time.

Although we had a total sample size of nine, each possum was only sampled once in this study across two nights. The lack of activity in some possums could be explained by other factors outside the scope of this study that would become more evident if each possum was repeatedly sampled across multiple nights. If this study was to be repeated in the future it would be valuable to not only increase the sample size but sample individuals more than once to get a better understanding of their behaviour under a variety of conditions.

I was confident that my presence would have a minimal effect with the engagement of a novel object and the experimental treatments would not be actively avoided unless they were unattractive compounds and therefore could successfully move forward with active semiochemical presentations.

\section{Semiochemicals as lures}

Since their discovery in the 1960 's, behavioural ecologist have been highly interested in the biological purpose and behavioural response to pheromones. Pheromones have been extensively researched in insects and thousands of insect pheromones have been discovered (Levison, 1975; Silverstein, 1981; Mennill et al, 
2011, Renou and Gurrero et al, 2000). Insect's pheromones have successfully been used by land managers for pest control (Barclay and Driessche, 1983). Land managers have had success using insect pheromones as baits and lures for mass trapping and metabolic disruption leading to a mass reduction in insect pest numbers and in some cases total eradication (Christensen, 1976. El-sayed, 2009; Renou and Gurrero et al, 2000).

Pheromone lures have shown their potential in insects and research is beginning to show that they may have similar successes in mammals (Silverstein, 1981; Humpheries et al, 1999, Roberts et al, 2010). The Australian brushtail possum is a prime candidate for the development of a pheromone lure. Possums are solitary, nocturnal and arboreal marsupials which rely heavily on olfactory communication to communicate with their conspecifics (Mclean, 2012). A scent mark is typically used to convey information about the signaller's sex, dominance status, condition and reproductive availability (Jolly et al, 1999). Possums scent mark through several glands located on the chin, sternum and cloaca (Mclean, 2014). Whilst little is known about the chemistry of the compounds in these glands, field and colony studies have shown that possums will investigate the urine of other possums (Kelly, unpublished honours thesis; Linklater, unpublished). It is believed that this is because there are semiochemicals produced by the holocrine and apocrine glands in the possum's cloaca which are used in olfactory communication. Which are expressed through the urine (Woodhouse et al., 1994). In a field study, several of these compounds had a statistically significant positive association with possum attraction (Linklater, unpublished).

The aim of the second experiment in this study was to find out which of the compounds that had been positively associated with attraction were the most 
attractive. I hypothesised that the compounds that would be most attractive to the colony would be those belonging to the acids and alcohols group identified by McLean (2014) as these compounds were known to act as pheromones in other species.

Some semiochemicals clearly were much more attractive than others. Of the original 16 compounds (urinary and food based) tested, five compounds (2- butanone, tert-butyl-ethyl ether, phenol, 3-methyl phenol and Acetone) out preformed both the controls and the standard in at least two of the behaviours measured and two (2Butanone and propane, 2-ethoxy-2methyl-/tert-butyl-ethyl ether) were more attractive than the control and standard for all three behaviours measured.

Those compounds which were most attractive to the colony were those found in the ketone, alcohol and phenol groups. These compounds are volatile compounds and belong to chemical groups which are used by many different species as pheromones (Mclean, 2012). Ketones are sex pheromones which have a range of biological functions. In cockroaches, for example, the are used in male-male interactions (Moore et al., 1995), whilst in garter snakes (Mason et al., 1989; Lemaster et al.,2002) and the white spotted Logicorn beetle they are sex pheromones used in both male-female and female- male interactions (Yasui et al., 2003, Miller et al.,2011). Ketones are also used as aggregation pheromones in flies (Moats $e t$ al., 1987; Hong Tan et al.,2014). Alcohols are used across the animal kingdom as pheromones in a variety of different ways (Heath et al., 1992). Phenols are also common sex and aggregation pheromones (Moats et al.,1987; Torto et al., 1994; Whittle et al.,2000). 
Acetone was the only food based compound that out-performed its control. Acetone is a common food additive in processed foods but it also naturally occurs in foods such as pumpkin and nuts (Jackson, unpublished). Acetone is also a compound used as a sex pheromone in vertebrates which is perhaps why it out preformed the other food based compounds (Fales et al., 1972).

It is possible that the most attractive compounds are used as sex pheromones in possums (Witzgall et al.,2010; Mclean, 2014). Sex pheromones can be used as communication within or between the sexes (Lemaster and Mason, 2002). In this study, I did not compare the response of male possums and the response of female possums to the same compounds as there were only two females in this study.

It has been theorised by behavioural ecologists that mammalian olfactory communication is quiet complex (Renou and Gurrero et al, 2000). Because of its complexity, the utilisation of mammalian pheromones in pest control has been slow (Brennan and Kendrick, 2006). However, this study shows that it is possible to get a response from a single compound alone. These result, show that some compounds found in the urine of possums are approached faster, sniffed and grabbed for longer than their controls and a commercially available bait commonly used in possum traps. The next step would logically be field trials and to test whether combinations of the five semiochemicals improve on their individual performance. As mentioned in Chapter two, there were constraints on colony size. Perhaps if these constraints could be circumvented, future studies would be able to produce a statistically clearer result (Stoinski et al., 2012). I would recommend that sample size was increased either through increasing the number of individuals (through larger colony sizes or by cycling through individuals) or by presenting the compounds multiple times to each possum (Todd et al., 2000; Merz, unpublished). Field trials where semiochemicals 
can be presented as multiple sets and populations would also be informative. Lastly it would be interesting to test if combining single semiochemicals illicit an even stronger response

\section{Final Conclusions}

There were two aims to this study, the first was to develop a protocol for active presentations in a small research colony (by testing for an observer effect). The second was to use the protocol to test the attractiveness of compounds (which had previously been positively associated with possum attractiveness) compared to their controls and a standard.

I found that there was no statistically significant evidence of an observer effect in the colony, and therefore active compound presentations would be able to proceed. Using an active compound presentation method, I found, five compounds were approached faster and sniffed for longer than their controls or the reference.

For future studies; 2- butanone, tert-butyl-ethyl ether, phenol, 3-methyl phenol and Acetone all showed potential as a long-life lure for possum pest control in New Zealand. A restricted sample size moreover shows that further research is needed to fully develop these compounds into long life-lures. However, this study shows that there is potential for successful pheromone lures to be created from single compounds. 


\section{References}

Archunan, G., (2009). Vertebrate pheromones and their biological importance. Journal of Experimental Zoology India. 12(2), 227-239.

Baker, R.L. and McGuffin, M.A., (2007). Technique and observer presence affect reporting of behaviour of damselfly larvae. Journal of the North American Benthological Society. 26(1), 145-151.

Barclay, H. and Van den Driessche, P., (1983). Pheromone trapping models for insect pest control. Researches on Population Ecology. 25, 105-115.

Balcombe, J., Barnard, N.D and Sandusky, C. (2004). Laboratory routines cause animal stress. Journal of the American Association for Laboratory animal science. 43(6), 4251 .

Bee, M.A, Perrill, S.A., Owen, P.C (2000). Male green frogs lower the pitch of acoustic signals in defense of territories: a possible dishonest signal? Behavioural Ecology, 11(2). 169-177.

Bigiani, A., Mucignat-Caretta, C., Montani, G. and Tirindelli, R (2005). Pheromone reception in mammals. Reviews of Physiology, Biochemistry and Pharmacology. 155, 1-35.

Blum, M.S (1969). Insect pheromones. Annual review of Entomology. 14, 57-80.

Blum, M.S. and Brand, J.M (1972). Social Insect Pheromones: Their Chemistry and Function. Integrative and Comparative Biology, 12 (3), 553-576.

Bradbury, J.W and Vehrencamp, S.L., (1999). Economic models of animal communication. Animal Behaviour. 59, 259-268.

Brennan, P.A and Kendrick, K.M. (2006). Mammalian social odours: attraction and individual recognition. Philosophical Transactions: Biological Sciences. 361(1476), 2061-2078.

Brennan, P.A and Keverne, E.B (2004). Something in the air? New insights into mammalian pheromones. Current Biology. 14, 81-93.

Brennan, P.A and Zufall, F. (2006). Pheromonal communication in vertebrates. Nature,444, 308-315.

Brown, K.P \&amp; Sherley, G.H (2003). The Eradication of possums from Kapiti Island, New Zealand. Proceedings of the International conference on Eradication of Island Invasives. 46-52.

Bro-Jorgensen, J., (2009). Dynamics of multiple Signalling systems: animal communication in a world in flux. Trends in Ecology and Evolution. 25(5), 292-300.

Bossert, W.H and Wilson, E.O., (1963). The analysis of olfactory communication among animals. Journal of Theoretical Biology. 5,443-469. 
Candolin, U., (2003). The use of multiple cues in mate choice. Biological Reviews. 78, 575595.

Carey, P.W; O'connor, C.E; McDonald, R.M \&amp; Mathews, L.R (1997). Comparison of the attractiveness of acoustic and visual stimuli for brushtail possums. New Zealand Journal of Ecology. 24(4), 273-276.

Carter, A.J; Feeney, W.E., Marshal, H.H., Cowlishaw, G. and Heinsohn, R. (2012). Animal personality: what are behavioural ecologists measuring? Biological reviews. 88(2) $465-475$

Charlton, B.D (2014), Discrimination of sex and reproductive state in koalas, Phascolarctos cinereus, using chemical cues in urine. Animal Behaviour. 91, 119-125.

Christiansen, E., (1976). Pheromones in small rodents and their potential use in pest control. Proceedings of the $7^{\text {th }}$ Vertebrate Pest Conference. 11, 185-195.

Cleasby, I.A, Nakagawa, S. and Schielzeth, H. (2015). Quantifying the predictability of behaviour: statistical approaches for the study of between-indivdual variation in the within-individual variance. Methods in Ecology and Evolution, 6, 27-37.

Clinchy, M., Taylor, A.C., Zanette Y, Krebs, J. \& Jarmans, P.J (2004). Body size, age and paternity in common brushtail possums (Trichosurus Vulpecula). Molecular Ecology. $13,195-202$

Clout, M.N \&amp; Efford, M.G (1984). Sex differences in the dispersal and settlement of Brushtail Possums (Trichosurus Vulpecula). Journal of animal ecology. 53, 737-749.

Crawford, J.L; Mcleod B.J; Thompson, E.G \&amp; Hurst P.R (1998). Presence of males affects the incidence of ovulation after pouch young removal in brushtail possum (Trichosurus Vulpecula). Animal Reproductive Science. 51, 45-55.

Crofoot, M.C., Lambert, T.D., Kays, R. and Wikelski M.C, (2010). Does watching a monkey change its behaviour? Quantifying observer effects in habituated wild primates using automated radiotelemetry. Animal Behaviour, 80, 475-480

Cowan, P.E. (1989). Denning habits of common brushtail possums, Trichosurus Vulpecula, in New Zealand lowland forrest. Australian Wildlife Research. 16(1),63-78.

Cowan, P.E (1993). Effects of intensive trapping on breeding and age structure of brushtail possums, Trichosurus Vulpecula on Kapiti Island New Zealand. New Zealand Journal of Zoology. 20(1), 1-11

Cowan, P. and Clout, M (2000). Possums on the move: Activity patterns, home ranges and dispersal. The Brushtail Possum: Biology, impact and management of an introduced marsupial. Manaaki Whenua Press.

Cowan, P.E., Heath D.D \&amp; Stankiewicz M. (2002). Effects of season, age and sex on infection with endoparasites of brushtail possums, Trichosurus Vulpecula, from a forest/farmland site lower North Island, New Zealand. New Zealand Journal of Ecology. 29(2), 161-169. 
Dakin, R and Montgomerie, R., (2011). Peahens prefer peacocks displaying more eyespots, but rarely. Animal Behaviour. 82, 21-28.

Day, T.D., O’Connor, C.E, and Waas, J.T (2000). Den sharing behaviour of captive brushrail possum (Trichosurus Vulpecula). New Zealand Journal of Zoology. 27(3), 183-187.

Dix, G.I; Jolly, S.E; Buffon, S \&amp; Gardiner, A.I (1994). The potential of electric shock for the humane trapping of Brushtail Possums, Trichosurus Vulpecula. Wildlife research. 24,49-52.

Doty,R.L. (1986). Odour guided behaviour in mammals. Experientia. 42, 257-271.

Eason, C.T. \&amp; Jolly, S.E (1993). Anticoagulant efforts of Pindone in the Rabbit and Australian Brushtail Possum. Wildlife research. 20, 371-374.

Eisenberg, J.F and Kleiman, D.G., (1972). Olfactory communication in mammals. Annual review of Ecology and Systematics. 3, 1-32.

El-sayed, A.M., Suckling, D.M., Byers, J.A., Jang, E.B and Wearing, C.H (2009). Potential of "Lure and Kill" in long term pest management and eradication of invasive species. Journal of Economic Entomology. 102(3), 815-835

Endler, J.A (1993). Genral comments on the evolution and design of animal communication. Philosophical Transactions: Biological Sciences, 340(1292).215-225.

Fales, H.M., Blum, M.S and Brand J.M (1972). Alarm pheromones in the genus Manica derived from the mandibular gland. Journal of Insect Physiology. 18(6), 1077-1088.

Firestien, S. (2001). How the olfactory system makes sense of scents. Nature. 413, 211-218.

Glen, A.S., Warburton, B. and Coleman, M (2014). Comparison of camera traps and kill traps for detecting mammalian pests, a field trial. The New Zealand Journal of Zoology. $41(3), 155-160$

Gosling, L.M (1982). A reassessment of the function of scent marking in territories. Journal of Comparative Ethology. 60, 89-118.

Gosling, L.M and Roberts, S.C (2001). Scent-marking by male mammals: cheat proof signals to competitors and mates. Advances in the Study of Behaviour. 30, 169-217.

Grodin, J.G.J. and Davis, S.A (1995). Who dares, benefits: Predator approach behaviour in the guppy (Pocecilia reticulate) deters predator pursuit. Proceedings: Biological sciences. 259(1355), 193-200

Hasson, O., (1997). Towards a general theory of biological signalling. Journal of Theoretical Biology.185, 139-156.

Heath, R.R., Landolt, P.J., Dueben, B.D., Murphy, R.E and Schneider R.E (1992). Identification of male cabbage looper sex pheromone attractive to females. Journal of Chemical Ecology, 18(3), 441-453. 
Heymann, E.W (1998). Sex differences in olfactory communication in a primate, the moustached tamarin, Saguinus mystax (Callitrichinae). Behavioural Ecology and Sociobiology. 43,37-45.

Hong Tan, K., Nishida, R., Jang, E.B. and Shelly, T.E (2014). Pheromones, male lures and trapping of tephritid fruit flies. In T. Shelly et al (eds), Trapping and the dection, control and regulation of tephritid fruit flies. New York, USA: Springer Science+Buisness Media Dordrecht.

Hughes, N.K., Kelly, J.L and Banks, P.B (2012). Dangerous liasisons: the predation risks of reieving social signals. Ecology Letters. 15, 1326-1339

Hughes, N.K., Korpimaki, E., and Banks, P.B (2010). The predation risks of interspecific eavesdropping: weasel-vole interactions. Oikos. 119,1210-1216.

Humphries, R.E., Robertson, D.H.L., Beyob, R.J and Hurst, J.L., (1999). Unravelling the chemical basis of competitive scent marking in house mice. Animal Behaviour. 58, 1177-1190.

Hurst, J.L (1990). Urine marking in populations of wild house mice Mus domesticus Rutty.I.communication between males. Animal Behaviour. 40, 209-222.

Hurst, J.L and Beynon, R.J (2004). Scent wars: the chemobiology of competitive signalling in mice. BioEssays. 26(12), 1288-1298.

Hurst, J.L., Beynon, R.J., Roberts, S.C and Wyatt T.D. (2008). Chemical signals in Vertebrates 11. New York, USA: Springer Scence+Buisness Media.

Iredale, S.K., Nevill, C.H. and Lutz, C.K, (2010). The influence of observer presence on baboon (Papio spp.) and rhesus macacque (Macaca mulatta) behaviour. Applied Animal Behaviour Science, 122, 53-57.

Isaac, J.L, (2005). Demographics of an island possum. Australian Journal of Zoology. 53, 195-203

Jack, K.M., Lenz, B.B., Healan, E., Rudman, S., Schoop, V.A.M and Fedigan, L,(2008). The effects of observer presence on the behaviour of Cebus capucinus in Costa Rica. American Journal of Primatology, 70, 490-494.

Jackson M. (2017). Unpublished doctoral thesis.

Johnstone, R.A and Grafen, A (1993). Dishonesty and the handicap principle. Animal Behaviour. 46,759-764.

Jolly, S.E., Spurr, E.B and Cowan, P.E (1999). Social dominance and breeding success in captive brushtail possums, Trichosurus Vulpecula. New Zealand Journal of Zoology. 26(1), 21-25.

Kelly, L. (2014). Pheromone lures in pest control: attractiveness of conspecific urine in the brushtail possum. Unpublished BSc Honours thesis. Victoria University of Wellington, Wellington, New Zealand 
Kitchen, D.M., Seyfarth, R..M., Fischer, J and Cheney, D.L., (2003). Loud calls as indicators of dominance in male baboons. Behavioural Ecology and Sociobiology. 53(6), 374384 .

Kroodsma, D.E and Byers B.E., (1991). The function(s) of bird song. American Zoologist. 31(2), 318-328.

Laidre, M.E., (2009). How often do animals lie about their intentions? An experimental test. The American Naturalist. 173(3), 337-346.

Laumann, R.A., Moraes, M.C.B., Cokl, A. and Borges, M (2007). Eavesdropping on sexual vibratory signals of stink bugs (Hermiptera: Pentatanidae) by the egg parasitoid Telenomus Podisi. Animal Behaviour. 73(4), 637-649

Lay, D.C., Buchanan, H.S. and Haussmann, M.F., (1999). A note on simulating the 'observer effect' using constant photoperiod on nursery pigs. Applied Animal Behavioural Science, 63, 301-309.

Little, E.C.S and Cowan P.E (1992). Natural immigration of brushtail possums, Trichosurus Vulpecula, onto Aroha Island, Kerikeri inlet, Bay of Islands, New Zealand. New Zealand Journal of Zoology. 19, 53-59.

Lemaster, M.P and Mason R.T (2002). Variation in female sexual attractiveness pheromone controls male mate choice in garter snakes. Journal of Chemical Ecology. 28(6), 1269-1285

Leruste, H., Bokkers, E.A.M., Sergent, O., Wolthius-Fillerup, M., Van Reenen, C.G. and Lensink, B.J (2013). Effects of the observation method (direct v.from video) and of the presence of an observer on behavioural results in veal calves. Animal. 7(11), 18581864.

Levinson, H.Z (1975). Possibilities of using insectistatics and pheromones in pest control. Naturwissenschaften. 62, 272-282.

Lewejohann, L., Zipser, B. and Sachser, N., (2011). "Personality" in laboratory mice used for biomedical research: a way of understanding variability. Developmental

Psychobiology. 53, 624-630.

Linklater, W. (2014). Attractiveness of possum urine compared to a control. Unpublished raw data

Marler, P., (1967). Animal communication signals: we are beginning to understand how the structure of animal signals relates to the function they serve. Science. 157, 769-774.

Mayer-Gross, H., Crick, H.Q.P and Greenwood, J.J.D., (1997). The effect of observers visiting the nests of passerines: an experimental study. Bird study, 44(1), 53-65.

Mayard-Smith, J and Harper, D.G.C (1995). Animal Signals: Models and terminology. Journal of Theoretical Biology. 177, 305-311

Mclean S., Davies, N. \&amp; Wiggins, N.L (2012). Scent chemicals of the Brushtail possum, Trichosurus Vulpecula. Journal of chemical ecology. 38, 1318-1339. 
Mclean, S (2014) Scent glands of the common brushtail possum (Truchosurus Vulpecula).New Zealand journal of ecology. DOI: 10.1080/03014223.2014.899506.

Mason, R.T., Fales, H.M., Jones, T.H., Pannell, L.K., Chinn, J.W and Crews, D. (1989). Sex pheromones in snakes. Science, 245,290-293.

Mennill, D.J., Ratcliffe, L.M. and Boag, P.T. (2002). Femal eavesdropping on male song contests in songbirds. Science. 296, 873.

Mennill, D.J and Ratcliffe, L.M (2002). Overlapping and matching in the song contests of black-capped chickadees. Animal Behaviour. 67, 441-450.

Miller, D.R., Asaro, C., Crowe, C.M and Duerr, D.A (2011). Bark beetle pheromones and pine volitiles: Attractant kairomome lure blend for longhorn beetles (Cerambycidae) in pine stands of the Southeastern United States. Journal of Economic Entomology. 104(4). 1245-1257.

Merz, R. (2017). Unpublished raw data.

Moats, R.A., Bartelt, R.J., Jackson, L. and Schaner A.M (1987). Ester and Ketone components of aggregation pheromone of Drosophila hydei (Diptera:Drosophilidae). Journal of Chemical Ecology, 13(3), 451-462.

Mockett, L (2014). Unpublished Victoria University of Wellington Summer Scholarship report.

Mockett, L (2015). Personal observations

Mondor, E.B and Roitberg, B.D. (2004). Inclusive fitness benefits of scent marking predators. Biology letters. 271, 341-343.

Moore, A.J., Reagan, N.L., Haynes, K.F (1995). Conditional signalling strategies: effects of ontogeny, social experience and social status on the pheromonal signal of male cockroaches. Animal Behaviour, 50. 191-202.

Morgan, K.N and Tromborg, C.T (2007). Sources of stress in captivity. Science Direct. 102, 262-302.

Morgan, D.R., Innes, J., Frampton, C.M and Woolhouse A.D (1995). Responses of captive and wild possums to lures used in poison baiting. The New Zealand Journal of Ecology. 22(2), 123-129.

National Research Council (2008). Recognition and allevation of distress in Laboratory animals. Committee on Recognition and Alleviation of Distress in Laboratory Animals.

Neumann, C., Assahad, G., Hmmerschmidt, K., Perwitasari-Farajallah, D. and Engelhardt, A., (2010). Loud calls in male crested macaques, Macaca nigra: a signal of dominance in a tolerant species. Animal Behaviour. 79, 187-193.

Noldus Information Technology. 2008. The Observer XT 8.0 [Computer software], Wageningen: Noldus Information Technology 
Osorio, D. and Vorobyev, M. (2008). A review of the evolution of animal colour vision and visual communication signals. Vision Research. 48, 2042-2051. Research gate

Owen, H.J AND Norton, D.A (1994). The diet of introduced brushtail possums Trichosurus vulpecula in a low density New Zealand Nothofagus forest and possible implications for conservation management. Biological conservation. 71, 339-345.

Parkes, J \&amp; Murphy, E (2003). Management of introduced mammals in New Zealand. The New Zealand Journal of Ecology. 30(4), 335-359.

Peters, R.P and Mech, L.D (1975). Scent marking in wolves: radio-tracking of wolf packs has provided definite evidence that olfactory sign is used for territory maintenance and may serve for other forms of communication with the pack as well. Sigma Xi,63(6), 628-637.

Powelsland, R.G., Kniegtmans, J.W and Marshell, I.S.J (1999). Costs and benefits of aerial 1080 possum control opperations using carrot baits to north island robins (Pectroica australis longpes) Pureora Forest Park. The New Zealand Journal of Ecology. 23(2), 149-159

Preuschoft, S. and van Schaik, C.P. (2000). Dominance and communication: conflict management in various social settings. In F. Aureli and F.B.M De Waal (eds), Natural resolution conflict. California, USA, University of California Press.

Renou, M. and Guerrero, A. (2000). Insect parapheromones in olfaction research and semiochemicals-based pes control strategies. Annual Review of Entomology. 48, 605630.

Recarte, J.M., Vincent, J.P and Hewison, A.J.M (1998). Flight responses of fallow deer to the human observer. Behavioural processes. 44, 65-72.

Roberts, S.A., Simpson, D.M, Armstrong, S.D., Davidsons, A.J., Robertson, D.H., McLean, L., Beynon, R.J and Hurst, J.L. (2010). Darcin: a male pheromone the stimulates female memory and sexual attraction to an individual male's odour. BMC Biology. $8(75), 1-21$.

Roche, D.G., Careau, V and Binning, S.A (2016). Demystifying animal personality (or not): why individual variation matters to experimental biologist. Journal of Experimental Biology, 219, 3832-3843.

Ross, J.G; Hickling, G.J; Morgan, D.R \&amp; Eason, C.T (2000). The role of non toxic prefeed and post feed in the development and maintenance of 1080 bait shyness in captive brushtail possums. Wildlife Research. 27, 69-74

Rousing, T. and Waiblinger, S., (2004). Evaluation of on farm methods for testing the human-animal relationship in dairy herds with cubicle loose housing systems -testretest and inter-observer reliability and consistency to familiarity of test person. Applied Animal Behaviour Science, 85, 215-231.

Rousing, T., Ibsen, B. and Sorensen, J.T (2005). A note on: on-farm testing of the behavioural response of group-housed calves towards human observers test-retest and 
inter-observer reliability and effect of familiarity of test person. Applied Animal Behaviour Science. 94, 237-243

Rowell, J.T., Ellner,S.P and Reeve, H.K (2006). Why animals lie: how dishonest and belief can coexist in a signalling system. The American Naturalist, 168(6). 180-204.

Salamon, M., Davies, N.W. and Stoddart, D.M., (1999). Olfactory communication in australian marsupials with particul reference to brushtail possum, koala and eastern grey kangaroo. Chemical signals in Vertebrates. 6, 85-95.

Saleh, N., Scott, A.G. and Bryning, G.P. (2007). Distinguishing signals and cues: bumblebees use general foot prints to generate adaptive behaviour at flowers and nest. Arthropodplant Interaction. 1, 119-127.

Searcy, W.A. (1992). Song repertoire in mate choice in birds. American Zoologist. 32(1), 7180.

Seyfarth, R.M and Cheney, D.L. (2003). Signallers and recievers in animal communication. Annual Review of Psychology. 54,145-173.

Silverstein, R.M (1981). Pheromones: Background and potential for use in insect pest control. Science. 213(4514, 1326-1332.

Smith, B.R and Blumstien, D.T (2008). Fitness consequences of personality: a meta-analysis. Behavioural Ecology. 19, 448-455.

Smith, J.L.D., McDougal, C. and Miquelle, D. (1989). Scent marking in free ranging tigers Panthera tigris. Animal Behaviour. 37, 1-10.

Sorensen,P.W (1996). Biological responsiveness to pheromones provides fundamental and unique insight into olfactory function. Chemical senses, 21(2), 245-256.

Sorensen, P.W and Stacey, N.E (2004). Brief review of fish pheromones and discussion of their possible uses in the control of non-indigenous teleost fishes. New Zealand Journal of Marine and Freshwater Research, 38(3), 399-417.

Stoinski, T.S., Jaicks, H.F and Drayton, L.A (2012). Visitor effects on the behaviour of captive western lowland gorillas: the importance of individual differences in examining welfare. Zoo Biology. 31, 586-599.

Szamado, S. (1998). Cheating as a mixed strategy in a simple model of aggressive communication. Animal behaviour, 59, 221-230.

Tetley, C.L and O'Hara, S.J (2012). Ratings of animal personality as a tool for improving the breeding management and welfare of zoo animals. Animal Welfare. 21, 463-476.

Tompkins, D.M \&amp; Ramsey, D. (2007). Optimising bait station delivery of fertility control agents of brushtail possum populations. Wildlife research. 34, 67-76.

Todd J., O'Connor C. \& Waas J. (1998). Laboratory evaluation of odor preferences of the brushtail possum. J. Chem. Ecol., 24, 439-449. 
Todd, J., Waas, J.R., and O'Connor, C.E (2000). Do brushtail possums (Trichosurus vulpecula) show preferences for exogenous odours associated with food? New Zealand Journal of Zoology. 27(1), 49-55

Torto, B., Obeng-Ofori, D., Njagi, N., Hassanali, A. and Amiani, H. (1994). Aggregation pheromone system of adult gregarious desert locust schistocerca gregaria (forskal). Journal of Chemical Ecology, 20(7),1749-1762.

Wade, M.R., Zalucki, M.P. and Franzmann, B.A, (2005). Influence of observer presence of Pacific Damsel Bug behaviour: Who is watching whom?. Journal of Insect Behaviour, 18(5), 651-667.

Walton, A. and Toth, A.L (2016). Variation in individual worker honey bee behaviour shows hallmarks of personality. Behavioural Ecology and Sociobiology. 70, 999-1010.

Warburton, B and Drew, K.W (1994). Extent and Nature of Cyanide-Shyness in some populations of Australian Brushtail possums in New Zealand. Wildlife research. 21,599-605.

Warburton, B. and Orchard, I (2010). Evaluation of 5 kill traps for effective capture and killing of Australian brushtail possums (Trichosurus vulpecula). New Zealand Journal of Ecology. 23(4), 307-314

Wellington City Weather - NZ Weather Forecast for MetService.com (n.d). Retrieved May 6, 2016 from http://www.metservice.com/towns-cities/wellington/wellington-city

Whiting, M.J., Webb, J.K and Keogh, J.S (2009). Flat lizard female mimics use sexual deception in visual but not chemical signals. Proceedings of the Royal Society. 276, 1585-1591.

Whittle, C.L, Bowyer, R.T., Clausen, T.P and Duffy, L.K (2000). Putatuve pheromones in urine of rutting male moose (Alces alcoes): Evolution of Honest Advertisement. Journal of Chemical Ecology, 26(12), 2747-2762.

Wich, S.A and Nunn, C.L. (2002). Do male "long-distance calls" function in mate defense? A comparative study of long-distance calls in primates. Behavioural Ecology and Sociobiology. 53(6), 474-484.

Wiley, R.H (2006). Signal detection and Animal Communication. Advances in the study of Behaviour,36. 217-247

Witzgall, P., Kirsch, P. and Cork, A. (2010). Sex pheromones and their impact on pest management. Journal of Chemical Ecology. 36, 80-100.

Woolhouse, A.D; Weston, R.J \&amp; Hamilton, B.H (1993). Analysis of secretions from scent producing glands of Brushtail possums (Trichosorus Vulpecula kerr). Journal of chemical ecology. 20(2), 239-253.

Wyatt, T.D. (2010). Pheromones and signature mixtures: defining species- wide signals and variable cues for identity in both invertebrates and vertebrates. 196, 685-700.

Yasui, H., Akino, T., Yasuda, T., Fukaya, M., Ono, H. and Wakamura, S. (2003), Ketone components in the contact sex pheromone of the white-spotted longicorn 
beetle, Anoplophora malasiaca, and pheromonal activity of synthetic ketones.

Entomologia Experimentalis et Applicata, 107, 167-176.

Zarzo, M (2007). The sense of smell: molecular basis of odorant recognition. Biological reviews, 82. 455-479.

Zuk, M. and Kolluru, G.R (1998). Exploitation of sexual signals by predators and parasitoids. The Quarterly Review of Biology. 73(4), 415-438.

Zuri, I., Su,W and Halpern, M., (2003). Conspecific odor investigation by grey short-tailed opossums (Monodelphis domestica). Physiology and Behaviour. 80(2-3),225-232. 